\title{
Empleabilidad y situación laboral de los egresados de Contaduría en México: Periodo 2005-2018
}

\section{Employability and employment status of accounting graduates in Mexico between 2005 and 2018}

DOI: https://doi.org/10.32870/dse.v0i21.640

\section{Javier Damián Simón*}

\begin{abstract}
Resumen
Debido a la escasa información sobre la situación laboral de los egresados de Contaduría a nivel nacional, en este artículo se presentan los resultados del análisis de 28 estudios de egresados llevados a cabo por 17 universidades ubicadas en 19 estados del país, en el cual participó una muestra de 5,120 egresados. El objetivo es describir algunos rasgos de la inserción laboral del contador, caracterizar al mercado de trabajo y determinar si les brinda las condiciones para su desarrollo laboral y profesional. Los resultados muestran altas tasas de inserción pero en condiciones de precariedad laboral, ubicándose en micro y pequeñas empresas del sector terciario en niveles operativos, desempeñándose como auxiliares contables o administrativos, con salarios bajos y jornadas laborales superiores a lo que dictan las leyes laborales. Se concluye que el mercado de trabajo presenta limitantes para que el contador pueda desarrollar en el mediano plazo trayectorias laborales ascendentes.
\end{abstract}

Palabras clave: contadores - mercado de trabajo - inserción laboral - egresados - universidad.

\begin{abstract}
Due to the limited information on the employment status of accounting graduates nationwide, this document presents the results of an analysis of 28 studies of alumni carried out in 17 universities located in 19 states of the country with a sample of 5,120 graduates. The aim is to describe some features of the insertion of accountants in the labor market, characterize this labor market, and determine if it provides the conditions for their professional development. The results show high insertion rates but conditions of precarious employment, being located in micro and small companies in the tertiary sector at operational levels, working as accounting or administrative assistants, with low salaries and longer working hours than those established by labor laws. We concluded that the labor market poses limitations for accountants to develop upward career paths in the medium term.
\end{abstract}

Keywords: accountants - labor market - labor insertion - graduates - university.

* Doctor en Enseñanza Superior. Profesor investigador en el Departamento de Ciencias Empresariales, Universidad del Papaloapan, Oaxaca, México. Línea de investigación: Estudiantes y egresados universitarios. damian_ce@hotmail.com 


\section{Introducción}

En México, para conocer la situación laboral de la población económicamente activa (PEA), se utiliza la Encuesta Nacional de Ocupación y Empleo (ENOE), preparada por el Instituto Nacional de Estadística y Geografía (INEGI), cuyo objetivo principal es proporcionar información sobre la población incorporada al mercado de trabajo y bajo qué condiciones lo ha hecho, la que está intentando incorporarse y aún no lo consigue, y la población ubicada al margen de dicho mercado (ENOE, 2010). Sin embargo, existen pocos estudios sobre el tema llevados a cabo desde el ámbito académico, entre estos está el realizado por Hernández, que indaga sobre el mercado de profesionistas en México y que surgió como un proyecto de la Asociación Nacional de Universidades e Instituciones de Educación Superior (ANUIES, 2003); el de Echavarría (2009), que focaliza el tema en Ciudad Victoria, Tamaulipas; el de Aguayo, Chapa y Rangel (2012), que se centran en el mercado de trabajo de la zona metropolitana de Monterrey; y el de Damián (2015; 2017), quien aborda el problema de la inserción laboral de egresados de carreras administrativas híbridas en el estado de Oaxaca.

Desde el ámbito gubernamental, algunos organismos se han interesado en el tema, y fue a partir de los años setenta cuando en México se empezaron a elaborar estadísticas para el ámbito laboral (INEGI, 2003). De acuerdo con datos proporcionados por FORBES (2015), la Secretaría de Trabajo y Previsión Social (STyPS) reporta que, en general, $80 \%$ de los profesionistas ocupados son trabajadores subordinados y remunerados, $6.4 \%$ son empleadores, $1 \%$ trabaja por cuenta propia y que $80.3 \%$ de los profesionistas trabajan en áreas que tienen alguna coincidencia con los estudios universitarios, siendo las áreas de educación y ciencias de la salud las que cuentan con mayor porcentaje de afinidad; mientras que de manera específica, aproximadamente $20 \%$ de los profesionistas ocupados en las áreas económico-administrativas e ingenierías trabajaban en ocupaciones no acordes con la formación profesional. De igual manera, en términos generales, los niveles salariales de los profesionistas difieren significativamente según la ubicación geográfica donde lleven a cabo su actividad laboral (Expansión, 2016): la Ciudad de México ofrece el mejor salario promedio mensual $(\$ 15,116.00)$, seguido de Baja California Sur $(\$ 13,781.00)$, Nuevo León $(\$ 13,383.00)$, Chihuahua $(\$ 12,971.00)$ y Querétaro $(\$ 12,841.00)$.

Lo más reciente en la materia es la ENOE, que a través de las variables acerca del contexto laboral, características de la unidad económica, jornada y regularidad laboral, ingresos y atención médica, trabajo secundario, búsqueda de otro trabajo, antecedentes laborales, y apoyos económicos, proporciona datos sobre el mercado laboral y ha permitido el análisis de su evolución en los tres últimos lustros, considerando los niveles de ocupación por sector de actividad económica y por entidad federativa. Sin embargo, la ENOE no presenta un análisis de la situación laboral de los profesionistas por carreras específicas, dejando un vacío de conocimiento en este tema; entonces, la justificación para esta investigación de corte exploratoria surge de dos intereses: 1) la necesidad de indagar aspectos muy particulares del mercado laboral del Licenciado en Con- 
taduría (LC) en México, tema que no se ha atendido y merece ser estudiado a profundidad, pues un alto porcentaje de estudiantes universitarios se ubican en este tipo de carrera y; 2) generar conocimiento en una línea de investigación emergente, a fin de compartirlos con los interesados en la temática. Al respecto, hay que aclarar que la información que se presenta en este trabajo es el producto de la recopilación y análisis de diversos estudios de egresados realizados en diversas universidades del país, que fueron efectuados en fechas distintas, con enfoques metodológicos cuantitativos y mixtos y con tamaños de muestra diferentes, por lo cual se reconoce que este análisis puede presentar algunas limitaciones metodológicas, pero que ante la falta de estudios a nivel nacional, se considera un esfuerzo valiosos para hacer un primer acercamiento exploratorio sobre la situación laboral de los egresados de esta profesión. El objetivo de este documento es caracterizar el mercado de trabajo para los contadores en nuestro país y determinar si el tejido empresarial les brinda las condiciones para su desarrollo laboral y profesional.

\section{Referentes teóricos}

\subsection{La Licenciatura en Contaduría y sus características}

La LC es un programa que se ofrece en la mayoría de las Instituciones de Educación Superior (IES), públicas y privadas del país; su orientación es estrictamente profesionalizante y busca una estrecha vinculación con los empleadores, mismos que les proporcionan información sobre los conocimientos y las exigencias que presentan, y que sirven de sustrato para que las IES preparen a los estudiantes en las diversas ramas de la actividad profesional y tengan un desempeño exitoso en el campo laboral (De Agüero y Torres, 2014).

La profesión contable en el país surge en el año de 1890, no obstante, uno de los eventos más significativos para formalizarla tuvo lugar en 1906, cuando se promulgó la Ley para la Enseñanza Comercial en el Distrito Federal cuyo objetivo era proporcionar un mayor estatus a las carreras que le antecedieron, como fue la Teneduría de Libros y Contabilidad Fiscal; así, un año después, el 25 de mayo de 1907, Fernando Diez Barroso presenta el primer examen profesional de Contador de Comercio que se expidió en México, hecho que marca el punto de partida de los 112 años de formación académica de la Contaduría Pública, lo que la convierte en una profesión con identidad propia y reconocimiento social en nuestro país (Espino, 2017). Con el incremento de IES que ofrecían la carrera en 1959, se funda la Asociación Nacional de Facultades y Escuelas de Contaduría y Administración (ANFECA), integrada originalmente por el Instituto Politécnico Nacional, el Instituto Tecnológico y de Estudios Superiores de Monterrey, las universidades autónomas de Coahuila, Chihuahua, Nuevo León, Puebla, Querétaro, San Luis Potosí, la Nacional Autónoma de México, y las universidades autónomas de Guanajuato, Sonora, Juárez del Estado de Durango, y la Universidad Veracruzana.

Hasta el periodo escolar del año 2017, la LC se ofrecía en 1,235 universidades y estaban matriculados 172,732 estudiantes, siendo cinco IES públicas las que presentan la mayor matrícula: 
Universidad Nacional Autónoma de México: 7,673 (52\% hombres, 48\% mujeres); Universidad Autónoma de Nuevo León: 5,304 (52\% hombres, 48\% mujeres); Instituto Politécnico Nacional: 4,333 (50\% hombres, 50\% mujeres); Universidad Autónoma de Sinaloa: 4,107 (45\% hombres, $55 \%$ mujeres) y la Benemérita Universidad Autónoma de Puebla: 3,832 (38\% hombres, 62\% mujeres). Las cifras muestran que la LC es una de las carreras del área económico-administrativa con mayor presencia en el ámbito laboral (tabla 1).

Tabla 1. Nivel de ocupación laboral de los egresados de carreras económico-administrativas

\begin{tabular}{|l|l|l|l|}
\hline \multicolumn{1}{|c|}{ Carreras universitarias } & Ocupados* & Hombres & \multicolumn{1}{c|}{ Mujeres } \\
\hline Administración y gestión de empresas & 852.1 & $55.1 \%$ & $44.9 \%$ \\
\hline Contabilidad y fiscalización & 716.7 & $51.9 \%$ & $48.1 \%$ \\
\hline Economía & 76.8 & $64.3 \%$ & $35.7 \%$ \\
\hline Finanzas, banca y seguros & 45.5 & $62.0 \%$ & $38.0 \%$ \\
\hline Mercadotecnia y publicidad & 130.9 & $48.5 \%$ & $51.5 \%$ \\
\hline $\begin{array}{l}\text { Negocios y administración, programas } \\
\text { multidisciplinarios o generales }\end{array}$ & 161.0 & $53.4 \%$ & $46.6 \%$ \\
\hline Negocios y comercio & 181.1 & $55.3 \%$ & $44.7 \%$ \\
\hline
\end{tabular}

* Cifras expresadas en miles de personas.

Fuente: Espino (2017).

Datos tomados del Instituto Mexicano para la Competitividad (IMCO, 2017) muestran que la condición laboral de los egresados de la LC, comparados con la media nacional de los egresados universitarios, es buena: ocupación (96.9\% contra 95\%), desempleo (3.1\% contra $4.2 \%)$ e informalidad (19.2\% contra 58.0\%). Por tanto, las estadísticas oficiales muestran que la profesión contable denota una alta competitividad en la oferta laboral para los candidatos a ingresar a estudios universitarios, situación que es necesario corroborar a través de la investigación sobre la situación laboral de los egresados de la LC en nuestro país.

\subsection{El diseño curricular de la Licenciatura en Contaduría}

Ante la abundancia de IES públicas y privadas que ofrecen esta carrera, a modo de ejemplo se describe a continuación el perfil de egreso y el plan de estudios de las dos IES más importantes en el país y de un subsistema de educación superior tecnológica que tiene presencia en todo el territorio nacional (tabla 2). 
Tabla 2. Cuadro comparativo del perfil de egreso del Licenciado en Contaduría Universidad Nacional Autónoma de México (2019)

El LC es un asesor en cuestiones financieras, de diseño e interpretación de sistemas de información financiera y contable para la toma de decisiones. Participa en la planeación estratégica y financiera, la evaluación de alternativas de financiamiento y estructura financiera de las organizaciones, evaluación de riesgos de carácter financiero, así como el diseño de sistemas de control interno de acuerdo con las buenas prácticas establecidas por las normas del gobierno corporativo en busca de la optimización de recursos. Participa en la evaluación y dictaminación de información financiera y fiscal, y promueve el cumplimiento de las obligaciones tributarias de las entidades a las que presta sus servicios; posee una perspectiva del ámbito de las actividades que realizan las organizaciones en general (públicas y privadas, con fines económicos o sociales) donde el sentido ético y de responsabilidad social guían su actuación profesional.

Instituto Politécnico Nacional (2019)

El Contador Público posee conocimientos para preparar y evaluar la información contable, financiera y administrativa para tomar decisiones en ambientes globalizados. Utiliza las tecnologías de la información y desarrolla sus actividades en apego a las disposiciones normativas vigentes y con ética profesional. Posee habilidades para proponer soluciones que fomenten la eficiencia y rentabilidad de las entidades en que se desarrolla. Responde a los valores de: calidad profesional de su trabajo, respeto a la dignidad del ser humano, integridad, responsabilidad, credibilidad y vocación de servicio.

\section{Tecnológico Nacional de México (2019) ${ }^{1}$}

El LC es un profesionista capaz de diseñar, establecer, aplicar, controlar y evaluar sistemas de información contable, administrativa, financiera y fiscal, para la toma de decisiones de las entidades económicas nacionales e internacionales; con una actitud ética, crítica, emprendedora y de liderazgo. Domina y aplica los principios de contabilidad generalmente aceptados y las normas y procedimientos de auditoría nacionales e internacionales; diseña, integra, implementa y controla sistemas de información contable, administrativa, fiscal, financiera y de costos, de entidades nacionales e internacionales y proporciona asesoría en estas áreas; diseña, asesora y propone estrategias para la toma de decisiones de inversión y financiamiento, para el desarrollo financiero competitivo de las entidades económicas; analiza, interpreta y dictamina la información financiera de una entidad económica para fundamentar la toma de decisiones; analiza, interpreta y aplica las leyes fiscales, mercantiles, civiles, laborales y ambientales que impactan a las entidades económicas en el ámbito federal, estatal y municipal, así como asesorar a las mismas en su cumplimiento; diseña y aplica una planeación financiera y fiscal en beneficio de las entidades $y_{i}$ conoce, cumple y promueve el código de ética profesional.

Fuente: Páginas web de las IES y del subsistema.

La tabla 3 muestra que el plan de estudios para la LC, sin importar la IES, está integrado en promedio por 50 asignaturas distribuidas en ocho o nueve semestres, o su equivalente en cuatrimestres; las asignaturas están agrupadas en por lo menos seis áreas importantes: contabilidad, administración, métodos cuantitativos, derecho, economía e informática y TIC, mismas

1 Se ofrece en sistema escolarizado en 52 planteles y en modalidad abierta y a distancia en cinco planteles.

Diálopos sobre Educación 
que persiguen el cumplimiento del perfil de egreso. Cabe aclarar que se ha dejado al arbitrio de cada IES el diseño y la administración del plan de estudios, por lo que en algunos casos se incluyen asignaturas optativas tanto de carácter general o profesionalizante, seminarios de investigación, asignaturas integradoras; en tanto que otras IES, a los cursos de idiomas, servicio social y prácticas en las empresas se les asignan créditos y forman parte del plan de estudios. 
Tabla 3. Comparativo del Plan de estudios de la Licenciatura en Contaduría

\begin{tabular}{|c|c|c|c|c|c|}
\hline \multicolumn{6}{|c|}{ Universidad Nacional Autónoma de México (semestres) ${ }^{2}$} \\
\hline Contabilidad & Administración & Matemáticas & Derecho & Economía & $\begin{array}{l}\text { Informática } \\
\text { yTIC }\end{array}$ \\
\hline $\begin{array}{l}\text { Contabilidad I, II, III, IV, V. } \\
\text { Sistemas de Control Interno. } \\
\text { Costos I, II. Finanzas I, III III, IV, } \\
\text { V. Contribuciones Indirectas } \\
\text { y al Comercio Exterior. Au- } \\
\text { ditoría I, II, III. ISR a Salarios y } \\
\text { Seguridad Social. Personas } \\
\text { Morales I, II. Personas Físicas. } \\
\text { Auditoría Interna. Presu- } \\
\text { puestos. }\end{array}$ & $\begin{array}{l}\text { Administración } \\
\text { Básica. Mercadotec- } \\
\text { nia. Diagnóstico de } \\
\text { Mercados. Control de } \\
\text { Gestión. }\end{array}$ & $\begin{array}{l}\text { Matemáticas } \\
\text { Financieras. } \\
\text { Estadística I, II. } \\
\text { Operaciones. } \\
\text { Razonamiento } \\
\text { Lógico-Mate- } \\
\text { mático. }\end{array}$ & $\begin{array}{l}\text { Conceptos Jurídicos } \\
\text { Fundamentales. De- } \\
\text { recho Mercantil. De- } \\
\text { recho Fiscal. Ética en } \\
\text { las Organizaciones. } \\
\text { Derecho Laboral. }\end{array}$ & $\begin{array}{l}\text { Microeconomía. } \\
\text { Teoría del Cono- } \\
\text { cimiento. Macro- } \\
\text { economía. Aná- } \\
\text { lisis del Entorno } \\
\text { Económico, Polí- } \\
\text { tico y Social. }\end{array}$ & $\mathrm{TICl}, \mathrm{II}$ \\
\hline \multicolumn{6}{|c|}{ Instituto Politécnico Nacional (niveles) ${ }^{3}$} \\
\hline $\begin{array}{l}\text { Fundamentos de contabili- } \\
\text { dad. Planeación financiera. } \\
\text { Ciclo financiero a largo pla- } \\
\text { zo. Costos predeterminados. } \\
\text { Tributación de personas } \\
\text { físicas. Fundamentos de } \\
\text { auditoría. Finanzas. Corpo- } \\
\text { rativas. Auditoría interna y } \\
\text { gobierno corporativo. } \\
\text { Estudio de capital contable. } \\
\text { Costos para la toma de deci- } \\
\text { siones. Estructura de tribu- } \\
\text { tación de personas morales. } \\
\text { Contabilidad corporativa. } \\
\text { Auditoría de estados finan- } \\
\text { cieros. Dictamen e informes } \\
\text { de estados financieros. } \\
\text { Análisis e interpretación de } \\
\text { la información financiera. } \\
\text { Seminario de impuestos y } \\
\text { casos especiales. Admón } \\
\text { de riesgos e instrumentos } \\
\text { derivados. }\end{array}$ & $\begin{array}{l}\text { Fundamentos de ad- } \\
\text { món. Fundamentos } \\
\text { de mercadotécnica. } \\
\text { Fundamentos de } \\
\text { comportamiento or- } \\
\text { ganizacional. Comer- } \\
\text { cio internacional. } \\
\text { Dirección estratégica. } \\
\text { Plan de negocios in- } \\
\text { tegral. }\end{array}$ & $\begin{array}{l}\text { Matemáticas } \\
\text { para los nego- } \\
\text { cios. }\end{array}$ & $\begin{array}{l}\text { Fundamentos de } \\
\text { derecho. }\end{array}$ & $\begin{array}{l}\text { Desarrollo } \\
\text { sustentable. } \\
\text { Fundamentos de } \\
\text { economía. Ma- } \\
\text { croeconomía. }\end{array}$ & $\begin{array}{l}\text { TIC. } \\
\text { Comunicación } \\
\text { oral y escrita. } \\
\text { Solución de } \\
\text { problemas y } \\
\text { creatividad. } \\
\text { Simulador de } \\
\text { negocios. }\end{array}$ \\
\hline
\end{tabular}

2 Incluye dos cursos de técnicas de investigación y nueve asignaturas optativas que el alumno deberá seleccionar de acuerdo con enfoque terminal que desee.

3 Incluye dos seminarios de investigación y tres tipos de optativas: tipo A (Métodos cuantitativos para la toma de decisiones; Contabilidad turística y de autotransporte; Motivación, conflicto y estrés en el trabajo, las relaciones humanas en la empresa; Psicología organizacional; Auditoría de calidad; Régimen fiscal del sector financiero; Impuestos al comercio exterior; Contribuciones relacionadas a remuneraciones al trabajo profesional), tipo B (Contabilidad de constructoras; Contabilidad de hospitales; Comunicación organizacional; Personalidad, ética y liderazgo; Administración del capital humano; Auditoría gubernamental; Auditoría ambiental; Auditorías fiscales; Contribuciones indirectas y estatales; Precios de transferencias; Procedimientos administrativos y defensa fiscal) y tipo C (Contabilidad de instituciones financieras; Contabilidad de instituciones de seguros; Contabilidad gubernamental; Seminario de tesis; Comportamiento directivo; Taller de desarrollo empresarial; Normas para atestiguary servicios relacionados; Finanzas internacionales; Planificación fiscal; Administración pública; Sistemas de información financiera; Finanzas públicas). 


\begin{tabular}{|c|c|c|c|c|c|}
\hline \multicolumn{6}{|c|}{ Tecnológico Nacional de México (semestres)4 } \\
\hline $\begin{array}{l}\text { Contabilidad básica. Con- } \\
\text { tabilidad intermedia I, II. } \\
\text { Teoría contable. Costos } \\
\text { históricos. Finanzas I, II, } \\
\text { III. Contabilidad superior. } \\
\text { Costos predeterminados. } \\
\text { Impuestos I, II, III. Auditoría } \\
\text { financiera I, II. Contabilidad } \\
\text { de sociedades. Presupues- } \\
\text { tos. Costos para la toma de } \\
\text { decisiones. Auditoría fiscal. } \\
\text { Seminario de contaduría. }\end{array}$ & $\begin{array}{l}\text { Admón general. } \\
\text { Admón de recursos } \\
\text { humanos I, II. Admón } \\
\text { de las operaciones. } \\
\text { Elaboración y evalua- } \\
\text { ción de proyectos. }\end{array}$ & $\begin{array}{l}\text { Matemáticas } \\
\text { administrati- } \\
\text { vas. Matemáti- } \\
\text { cas financieras. } \\
\text { Estadística } \\
\text { administrativa } \\
\text { I, II. }\end{array}$ & $\begin{array}{l}\text { Intr. al estudio del } \\
\text { derecho y dere- } \\
\text { cho civil. Dinámica } \\
\text { psicosocial. Derecho } \\
\text { constitucional, admi- } \\
\text { nistrativo e inter- } \\
\text { nacional. Derecho } \\
\text { laboral. Derecho } \\
\text { Mercantil. Semina- } \\
\text { rio de ética. Dere- } \\
\text { cho fiscal. }\end{array}$ & $\begin{array}{l}\text { Economía } \\
\text { empresarial. } \\
\text { Desarrollo sus- } \\
\text { tentable. Entor- } \\
\text { no macroeco- } \\
\text { nómico de las } \\
\text { organizaciones. } \\
\text { Economía inter- } \\
\text { nacional. }\end{array}$ & $\begin{array}{l}\text { Taller de in- } \\
\text { formática I, } \\
\text { II, III. }\end{array}$ \\
\hline
\end{tabular}

Fuente: Tomado de la página web de las instituciones analizadas.

\section{Marco metodológico}

El estudio fue descriptivo y exploratorio, con un enfoque cuantitativo; pretende describir el mercado de trabajo del contador en México a partir del análisis de estudios de egresados generados en los últimos 13 años; al no existir informes ni estadísticas puntuales sobre la situación laboral de los contadores en el país, se desconoce la composición numérica de la data estudiada, lo que impidió el cálculo estadístico de la muestra, tomándose como tal a la cantidad de documentos y reportes generados a partir del año 2005 a la fecha, en universidades públicas y privadas que abordaron la situación del mercado de trabajo de los egresados de la Licenciatura en Contaduría. ${ }^{5}$

Para obtener la información, se realizó una búsqueda de dos formas: 1) en bases de datos especializadas tales como EBSCO, ELSEVIER, Google Académico e IRIESE y, 2) en memorias con formato digital de IES u organismos que celebran de manera continua congresos nacionales e internacionales que incluyen la temática de egresados universitarios: Congreso Nacional de Investigación Educativa del Consejo Mexicano de Investigación Educativa (COMIE), celebrados bianualmente (2009, 2011, 2013 y 2015); Congreso Internacional de Contaduría, Administración e Informática de la Universidad Nacional Autónoma de México (2010-2016); y el Congreso Internacional de Contaduría, Administración e Informática Administrativa de la Universidad Michoacana de San Nicolás de Hidalgo, en sus siete versiones (2010-2016).

En el periodo de 2005 a 2018 se ubicaron 28 estudios (tabla 4), llevados a cabo por 17 IES públicas y dos privadas, ubicadas en 19 estados del paísy en contextos muy diferenciados, es decir, establecidas en grandes centros urbanos (capital del estado) y en poblaciones menores a 20,000 habitantes; 17 estudios abordaron la situación desde la opinión de los egresados, siete desde la opinión de los empleadores, y en cuatro se con-

4 Incluye tres asignaturas de investigación.

5 La carrera recibe varias denominaciones: Licenciatura en Contaduría (LC), Licenciatura en Contaduría Pública (LCP) y Contador Público (CP), existen variantes con una especialización terminal como Licenciatura en Contaduría Pública y Finanzas (LCPF) y Licenciatura en Contaduría Pública y Auditoria (LCPA). Al respecto, Torres (2014) menciona que existe una tendencia en el uso de nombres nuevos para la misma profesión, utilizando términos que dan la apariencia de modernidad.

Diálo@os 
trastaron las opiniones de ambos agentes. Los estudios comprendieron una muestra de 2,721 empleadores y 5,120 egresados de Contaduría, mismos que al momento del reporte del documento tenían un promedio de cuatro años de haber concluido los estudios universitarios, lo que permite conocer algunos rasgos de su inserción en el mercado de trabajo, tal como lo propone la ANECA (2009), Damián (2010) y Teichler (2003).

Tabla 4. Datos de procedencia de los documentos y reportes analizados

\begin{tabular}{|c|c|c|c|c|}
\hline Institución de Educación Superior & Tipo & Muestra & Autor y Año & Estado \\
\hline $\begin{array}{l}\text { Universidad Michoacana de San Nicolás } \\
\text { de Hidalgo }\end{array}$ & $\mathrm{CL}$ & $116 \mathrm{EM}$ & $\begin{array}{l}\text { Rodales y Chávez } \\
(2018)\end{array}$ & Michoacán \\
\hline $\begin{array}{l}\text { Benemérita Universidad Autónoma } \\
\text { de Puebla }\end{array}$ & ART & $\begin{array}{l}61 \mathrm{EG} y \\
19 \mathrm{EM}\end{array}$ & $\begin{array}{l}\text { Vera, Soriano y Linares } \\
(2017)\end{array}$ & Puebla \\
\hline Universidad Autónoma de Baja California & ART & $\begin{array}{l}38 \mathrm{EM} \mathrm{y} \\
52 \mathrm{EG}\end{array}$ & $\begin{array}{l}\text { Brito, Ferreiro y Garam- } \\
\text { bullo (2017) }\end{array}$ & $\begin{array}{l}\text { Baja California } \\
\text { Norte }\end{array}$ \\
\hline $\begin{array}{l}\text { Universidad Autónoma del Estado } \\
\text { de Hidalgo }\end{array}$ & RD & $68 \mathrm{EG}$ & Bezies, et al (2017) & Hidalgo \\
\hline $\begin{array}{l}\text { Universidad de Guadalajara. Centro } \\
\text { Universitario de los Altos }\end{array}$ & TM & $29 E G$ & Padilla (2017) & Jalisco \\
\hline $\begin{array}{l}\text { Universidad Autónoma del Estado } \\
\text { de México }\end{array}$ & TM & $61 \mathrm{EG}$ & Morales (2016) & Edo. de México \\
\hline Universidad Autónoma de Tamaulipas & ART & $\begin{array}{l}64 \mathrm{EG} \mathrm{y} \\
850 \mathrm{EM}\end{array}$ & $\begin{array}{l}\text { Leopoldo, Ramírez, } \\
\text { Cuarenta y José (2016) }\end{array}$ & Tamaulipas \\
\hline $\begin{array}{l}\text { Universidad Nacional Autónoma } \\
\text { de México. FES Cuautitlán }\end{array}$ & $\mathrm{PCl}$ & $489 \mathrm{EG}$ & $\begin{array}{l}\text { Martínez, Flores y Flo- } \\
\text { res (2015) }\end{array}$ & Edo. de México \\
\hline $\begin{array}{l}\text { Universidad de Guadalajara. Centro Uni- } \\
\text { versitario de los Altos }\end{array}$ & ART & $40 \mathrm{EG}$ & $\begin{array}{l}\text { González y Ortega } \\
(2015)\end{array}$ & Jalisco \\
\hline $\begin{array}{l}\text { Instituto Tecnológico y de Estudios } \\
\text { Superiores de Monterrey. s/d }\end{array}$ & $\mathrm{PCl}$ & $899 \mathrm{EM}$ & Montoya y Farías (2013) & Nacional (IMCP) \\
\hline Universidad Autónoma de Chiapas & $\mathrm{PCl}$ & $25 \mathrm{EM}$ & Román y Franco (2014) & Tuxtla Gutiérrez \\
\hline Universidad Autónoma de Baja California & $\mathrm{CL}$ & $179 \mathrm{EG}$ & $\begin{array}{l}\text { Talavera, Plazola y Berre- } \\
\text { lleza (2013) }\end{array}$ & $\begin{array}{l}\text { Baja California } \\
\text { Norte }\end{array}$ \\
\hline Universidad Autónoma de Tlaxcala & $\mathrm{CL}$ & $37 \mathrm{EG}$ & $\begin{array}{l}\text { Quintana, Mitre y Sán- } \\
\text { chez (2013) }\end{array}$ & Tlaxcala \\
\hline $\begin{array}{l}\text { Universidad Autónoma del Estado } \\
\text { de México }\end{array}$ & $\mathrm{CL}$ & $326 \mathrm{EG}$ & $\begin{array}{l}\text { Palma, Pérez y Vilchis } \\
\text { (2013) }\end{array}$ & Edo. de México \\
\hline Universidad Autónoma del Carmen & $\mathrm{CL}$ & $21 \mathrm{EG}$ & $\begin{array}{l}\text { López, González y Rodrí- } \\
\text { guez (2013) }\end{array}$ & Campeche \\
\hline Universidad Autónoma de Coahuila & $\mathrm{PCl}$ & $284 \mathrm{EM}$ & $\begin{array}{l}\text { Gutiérrez, Zúñiga y Gon- } \\
\text { zález (2012) }\end{array}$ & Coahuila \\
\hline Universidad Estatal de Sonora & $\mathrm{RD}$ & $31 \mathrm{EG}$ & Munguía y Quintal (2012) & Sonora \\
\hline Universidad Autónoma de Chihuahua & PCN & 377 EG & $\begin{array}{l}\text { Treviño, Polanco y Porras } \\
(2012)\end{array}$ & Chihuahua \\
\hline
\end{tabular}




\begin{tabular}{|l|l|l|l|l|}
\hline Universidad Autónoma de Chiapas & ART & 349 EM & Román y Enciso (2012) & Chiapas \\
\hline Universidad Juárez del Estado de Durango & RD & $\begin{array}{l}\text { Solo por- } \\
\text { centajes }\end{array}$ & $\begin{array}{l}\text { Carrera, Gómez y Pérez } \\
\text { (2012) }\end{array}$ & Durango \\
\hline $\begin{array}{l}\text { Universidad Autónoma del Estado de México. } \\
\text { Centro Universitario UAEM Amecameca }\end{array}$ & CL & 220 EG & $\begin{array}{l}\text { Rodríguez, Cotera y So- } \\
\text { beranes (2012) }\end{array}$ & Edo. de México \\
\hline Universidad Autónoma de Campeche & PCI & 20 EM & $\begin{array}{l}\text { Javier, Arguelles y Aké } \\
\text { (2011) }\end{array}$ & Campeche \\
\hline Universidad Autónoma de San Luis Potosí & PCI & 99 EM & $\begin{array}{l}\text { Gamboa, Vázquez } \\
\text { y Hernández (2011) }\end{array}$ & San Luis Potosí \\
\hline Universidad Autónoma de Chihuahua & PCN & 64 EG & $\begin{array}{l}\text { Treviño, Anchondo y } \\
\text { Polanco (2011) }\end{array}$ & Chihuahua \\
\hline $\begin{array}{l}\text { Universidad Michoacana de San Nicolás } \\
\text { de Hidalgo }\end{array}$ & CL & 611 EG & $\begin{array}{l}\text { Toscano, Toscano y Tos- } \\
\text { cano (2011) }\end{array}$ & Michoacán \\
\hline Universidad Autónoma de Puebla & RD & 1,834 EG & Hernández (2009) & Puebla \\
\hline Universidad Anáhuac del Mayab & PCN & $\begin{array}{l}75 \mathrm{EG} \mathrm{y} \\
22 \mathrm{EM}\end{array}$ & $\begin{array}{l}\text { Guzmán, Febles y Corre- } \\
\text { dera (2007) }\end{array}$ & Yucatán \\
\hline Universidad Autónoma de Coahuila & PCN & $450 \mathrm{EG}$ & $\begin{array}{l}\text { Ruiz, Zúñiga y González } \\
\text { (2005) }\end{array}$ & Coahuila \\
\hline
\end{tabular}

TM: Tesis de maestría; PCI: Ponencia en Congreso Internacional; PCN: Ponencia en Congreso Nacional; ART: Artículo de revista; RD: Reporte de diagnóstico; CL: Capítulo de libro; EG: Egresados; EM: Empleadores. Fuente: elaboración propia con datos obtenidos de los documentos analizados.

Para el tratamiento y análisis de los documentos, se realizó una lectura minuciosa con el fin de identificar las variables en común, pues si bien se reconoce que las IES siguieron la metodología que propone la ANUIES, todas efectuaron modificaciones, empleando solo aquellas variables que resultaron ser de su interés particular; por ello se seleccionaron los aspectos en común para llevar a cabo un análisis comparativo de la situación, se utilizó estadística descriptiva básica, se organizó la información en tablas de doble entrada y en algunas gráficas, a fin de facilitar la comprensión del tema a los lectores interesados.

\section{Principales hallazgos}

Por razones de espacio, en este apartado se hace una descripción muy puntual de los resultados a la luz de la teoría existente sobre el tema, invitando a los interesados a la lectura minuciosa de los documentos que se listan en las referencias bibliográficas; los resultados se presentan organizados en tres apartados.

\subsection{Datos generales de los egresados de Contaduría}

Del total de 5,120 contadores que se reportaron en los estudios de egresados analizados, $64.23 \%$ son mujeres (casi dos terceras partes) y $35.77 \%$ hombres, indicativo de que esta carrera está permeada por la condición de género; la edad promedio es de 25.25 años; siendo en su mayoría solteros (71\%), casados (23\%), divorciados (1\%) y en unión libre (5\%); el 76\% está titulado. 


\subsection{Características del mercado de trabajo para el egresado de Contaduría}

\subsubsection{Nivel de ocupación del egresado de Contaduría}

En los documentos analizados se encontró que una alta proporción de los contadores trabajan actualmente (72\%), de estos, quizá debido a la tradición existente de empezar a efectuar prácticas en despachos durante su formación, 33.96\% reportó trabajar desde antes de terminar la universidad; en tanto $28 \%$ no labora, para dar continuidad a su formación académica (posgrado), por asuntos personales o porque no han encontrado trabajo todavía (9.91\%). Llama la atención que los resultados encontrados muestran una diferencia con lo reportado en las estadísticas oficiales pues el IMCO (2017) afirma que $96.9 \%$ de los egresados de contaduría están trabajando, contra 3.1\% que no lo hace, cifras que contrastan con lo encontrado en esta investigación, quizá debido a las diferencias en los periodos en los años de egreso, tamaño de la muestra u otros aspectos metodológicos que empleó el IMCO y que se desconocen.

Se encontraron cuatro razones principales para no trabajar: 1) falta de experiencia laboral, 2) los empleos ofrecidos no cumplen sus expectativas (salarios bajos, tipo de puesto o condiciones laborales no adecuadas), lo que hace evidente que los egresados hacen uso del salario de reserva, tal como lo proponen Hall y Lieberman (2005), 3) por deficiencia en la formación recibida y, 4) falta de dominio de otro idioma. La mayoría trabaja, "sin importar su posición jerárquica", como empleado en alguna organización (89\%), 6.20\% reporta ser emprendedor pues es propietario de algún negocio o empresa y $4.80 \%$ dice trabajar de manera independiente.

\subsubsection{Tiempo transcurrido para encontrar el empleo}

La figura 1 muestra que el egresado de contaduría se inserta prontamente en el mercado de trabajo pues más de la mitad (59\%) lo hace en menos de seis meses, en tanto que $87 \%$ lo encuentra en un periodo de un año. Sin embargo, estas elevadas proporciones no significan un cumplimiento real de la Teoría del Capital Humano en el sentido de que, a mayor escolaridad los individuos se insertan con mayores ventajas en el mercado de trabajo (Cardona et al., 2007), pues como se verá más adelante, las condiciones laborales que ofrece el tejido empresarial para los egresados generalmente son precarias en cuanto al nivel salarial, jornadas de trabajo, nivel jerárquico y tipo de actividades que desempeñan, razón por la cual estas tasas altas de inserción laboral deben interpretarse con cautela pues se debe reconocer que la dinámica entre los procesos educativos y las condiciones del sector empleador son cambiantes y en ocasiones divergentes (Planas, 2014). 
Figura 1. Tiempo que transcurre después del egreso para encontrar empleo

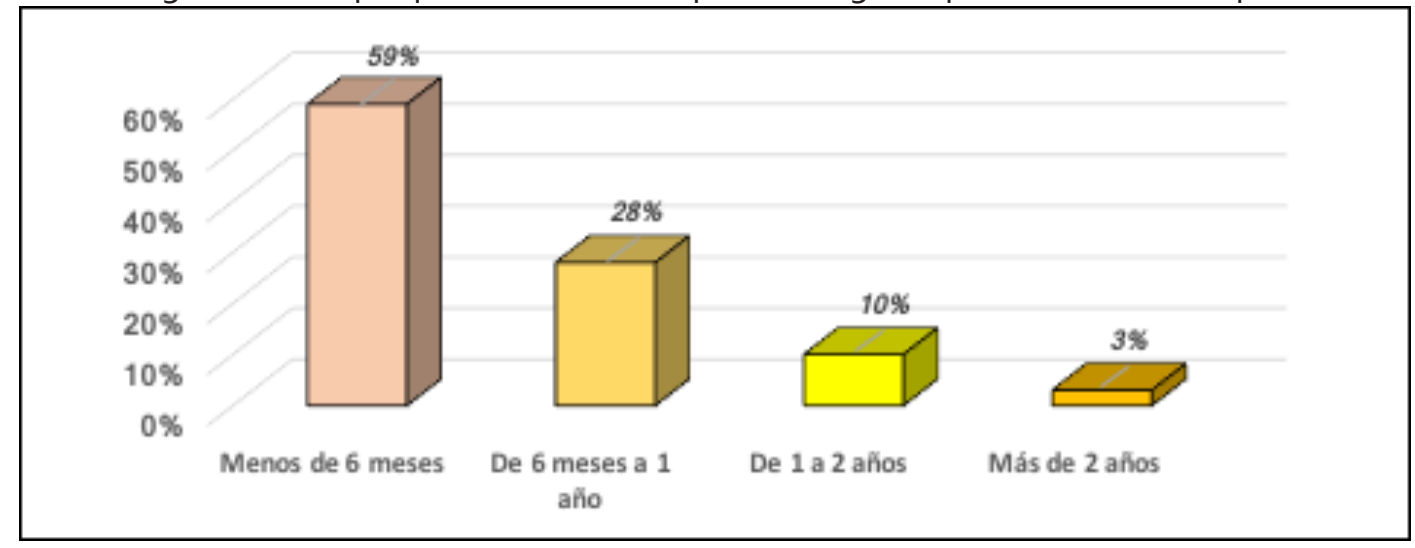

Fuente: elaboración propia con datos obtenidos de los documentos analizados.

\subsubsection{Limitantes para encontrar empleo y requisitos para obtenerlo}

En el caso de los egresados que enfrentaron demoras para la inserción laboral, la tabla 5 muestra en orden descendente que las tres limitantes principales fueron referidas por $68.86 \%$ de los egresados; en tanto, los dos requisitos de mayor peso para obtener el empleo según $44.73 \%$ de los egresados, fueron pasar una entrevista formal y mostrar experiencia laboral. Los egresados refieren dos limitantes para su inserción laboral, que a su vez se constituyen en requisitos indispensables para obtener el empleo en el mercado laboral: tener experiencia laboral (26.93\% contra $19.03 \%$ ) y estar titulado (5.48\% contra $10.56 \%)$.

Tabla 5. Limitantes y requisitos para que el egresado de contaduría obtuviera el empleo

\begin{tabular}{|l|l|l|c|}
\hline \multicolumn{1}{|c|}{ Limitantes } & $\%$ & \multicolumn{1}{c|}{ Requisitos } & $\%$ \\
\hline Escasa experiencia laboral & 26.93 & Pasar una entrevista formal & 25.70 \\
\hline El salario era el mínimo & 23.54 & Experiencia laboral & 19.03 \\
\hline No afín a su profesión & 18.39 & La edad & 17.74 \\
\hline Oferta poco atractiva & 8.31 & Aprobar examen de selección & 16.13 \\
\hline No dominar inglés u otro idioma & 5.70 & Prestigio de la institución & 10.84 \\
\hline No estar titulado & 5.48 & Tener título de licenciatura & 10.56 \\
\hline Por deficiencia en su formación profesional & 4.78 & & \\
\hline Situación personal & 4.26 & & \\
\hline Competencia de otras IES conocidas & 1.47 & & \\
\hline Falta de vacantes & 1.14 & & \\
\hline
\end{tabular}

Fuente: elaboración propia con datos obtenidos de los documentos analizados. 


\subsubsection{Tamaño de la empresa donde trabajan los egresados de Contaduría}

La figura 2 muestra que el mercado laboral para los contadores, en su mayoría son micro y pequeñas empresas (Mypes), quienes les brindan su primera oportunidad de trabajo, y en conjunto emplean a $64 \%$ de los egresados; o bien son micro, pequeñas y medianas empresas (Mipymes) que ofrecen plazas de trabajo para $77 \%$ de ellos, mientras que las oportunidades de trabajo en las grandes empresas son escasas pues solo dos de cada diez egresados trabajan en estas. Estos resultados son similares a los reportados en un estudio sobre el mercado laboral de los administradores en México (Damián, 2018), lo que corrobora la limitada capacidad de la estructura del tejido empresarial para el desarrollo laboral y profesional del egresado de contaduría, pues existe evidencia que, a medida que el tamaño de la empresa aumenta, también ofrece mejores condiciones laborales (BID, 2003); por lo cual, en el caso que nos ocupa existe una devaluación de la formación universitaria pues los perfiles de egreso del LC refieren que está capacitado para asumir responsabilidades y desempeñarse en niveles jerárquicos de alto nivel, situación que dista mucho de su cumplimiento.

Las limitantes del mercado del trabajo se comprueban, además, porque se observa que la situación no mejora con el paso del tiempo pues los egresados que han cambiado de empleo en varias ocasiones refieren que actualmente $52 \%$ (32\% y 20\%) trabajan en Mypes, $83 \%$ en Mipymes y $17 \%$ en empresas grandes, indicativo de las escasas posibilidades que tiene el entramado empresarial para ofrecer a los egresados migrar hacia puestos de trabajo en empresas de mayores dimensiones que ofrezcan mejores condiciones de trabajo.

Figura 2. Tamaño de las empresas donde trabajan los contadores

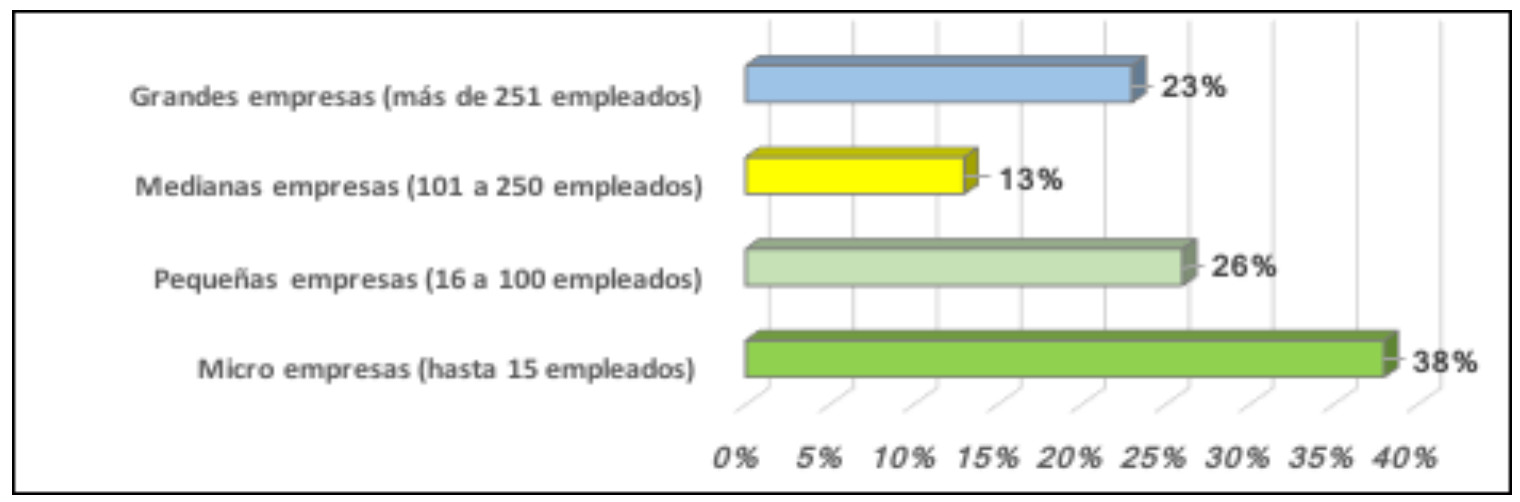

Fuente: elaboración propia con datos obtenidos de los documentos analizados.

\subsubsection{Régimen jurídico de las empresas, tipo de contrato otorgado, salario mensual y jornada laboral de los egresados de Contaduría}

Los egresados, en su mayoría, trabajan en empresas del sector privado (72.52\%), seguidas del sector público: $27.48 \%$ (estatal $56 \%$, federal $35 \%$ y municipal 9\%). El mercado de trabajo brinda a $56.46 \%$ de los egresados contratos por tiempo indeterminado, pero no ofrece seguridad ni estabilidad laboral a $43.54 \%$, quienes tie- 
nen contratos por tiempo determinado (25.76\%), honorarios (9.5\%), obra determinada (1.7\%) y de otro tipo (2.6\%), situación que prevalece desde el primer empleo hasta el actual.

Los niveles salariales son bajos. La tabla 6 muestra que $70.16 \%$ de los egresados tienen salarios mensuales menores a $\$ 10,000.00$, mientras que apenas un poco más de la cuarta parte obtiene ingresos por arriba de la cantidad anterior; esta situación se agudiza cuando se observa que $42.03 \%$ de los egresados tienen jornadas de trabajo que están más allá de las 40 horas semanales que contemplan las leyes laborales, predominando las jornadas de 41 a 50 horas, y se encontró que el horario semanal más alto está en el rango de 48 a 72 horas, mismo que pudiera considerarse como un factor para generar cansancio, fatiga y estrés entre los contadores (Pedraza, 2016).

Tabla 6. Salarios mensuales y jornadas de trabajo semanales de los contadores

\begin{tabular}{|l|c|l|c|}
\hline \multicolumn{1}{|c|}{ Salarios mensuales } & $\%$ & Jornadas de trabajo a la semana & $\%$ \\
\hline Menor o igual a $\$ 5,000$ & 37.31 & De 1 a 20 horas & 21.60 \\
\hline De $\$ 5,001$ a $\$ 10,000$ & 32.85 & De 21 a 30 horas & 14.77 \\
\hline De $\$ 10,001$ a $\$ 15,000$ & 21.94 & De 31 a 40 horas & 21.60 \\
\hline Más de $\$ 15,000$ & 7.90 & De 41 a 50 horas & 26.13 \\
\hline & & Más de 50 horas & 15.90 \\
\hline
\end{tabular}

Fuente: elaboración propia con datos obtenidos de los documentos analizados.

\subsubsection{Sector económico y rama donde laboran los egresados de Contaduría}

La tabla 7 muestra que el egresado de contaduría tiene un amplio abanico de posibilidades para su ejercicio profesional; sin embargo, una vez más, el débil tejido empresarial del país ocasiona un desequilibrio en la distribución de estos, siendo el sector terciario y sus subdivisiones (cuaternario y quinario) donde laboran la mayoría de los egresados (78.95\%), en las ramas del comercio (21.65\%) y servicio profesionales y técnicos (26.10\%); en el sector secundario (17.11\%), principalmente en la industria de la transformación y la construcción (13.02\%), en tanto el sector primario escasamente ofrece oportunidades laborales a los contadores. Por tanto, el tamaño y el sector económico al que pertenecen las empresas donde laboran los egresados bien pueden explicar los bajos salarios y las largas jornadas de trabajo de los contadores en los primeros años de su inserción laboral. 
Tabla 7. Sectores y subsectores económicos donde laboran los egresados de Contaduría

\begin{tabular}{|c|c|}
\hline Sector económico y su descripción & $\begin{array}{c}\text { Rama del sector y porcentaje } \\
\text { de ocupación }\end{array}$ \\
\hline $\begin{array}{l}\text { Primario: actividades de obtención, producción y extrac- } \\
\text { ción de recursos naturales de los subsectores agrícola, } \\
\text { pesquero, minero y forestal, para los sectores secundario y } \\
\text { terciario (3.94\%). }\end{array}$ & $\begin{array}{l}\text { Agrícola, ganadera, silvícola, etc.: } 2.87 \% \\
\text { Industria extractiva: } 1.99 \%\end{array}$ \\
\hline $\begin{array}{l}\text { Secundario: transformación de la materia prima en produc- } \\
\text { tos industrializados de alto valor agregado en productos } \\
\text { terminados o semielaborados o en maquinarias y herra- } \\
\text { mientas industriales. Actividades industriales, construc- } \\
\text { ción, procesamiento de alimentos, industria naval y aero- } \\
\text { náutica, etc. (17.11\%). }\end{array}$ & $\begin{array}{l}\text { Industria de la transformación: } 6.71 \% \\
\text { Industria de la construcción: } 6.31 \% \\
\text { Alimentos, bebidas y tabaco: } 4.09 \%\end{array}$ \\
\hline $\begin{array}{l}\text { Terciario: concerniente al comercio y prestación de ser- } \\
\text { vicios, desarrolla la distribución y comercialización de los } \\
\text { bienes tangibles e intangibles. Servicios comerciales, ban- } \\
\text { carios, turísticos, etc. (36.12\%). }\end{array}$ & $\begin{array}{l}\text { Comercio: } 21.65 \% \\
\text { Servicios bancarios, financieros y segu- } \\
\text { ros: } 7.62 \% \\
\text { Transporte/comunicación y telefonía: } \\
3.00 \% \\
\text { Turismo (hospedaje, alimentos y bebi- } \\
\text { das, esparcimiento, agencia de viajes): } \\
2.6 \% \\
\text { Inmobiliarios: } 1.00 \% \\
\text { Diseño gráfico: } 0.25 \%\end{array}$ \\
\hline $\begin{array}{l}\text { Cuaternario*: actividades donde el conocimiento se capi- } \\
\text { taliza como un bien, pero sin mecanizar: intelectuales de } \\
\text { investigación, desarrollo de proyectos de ciencia y tecno- } \\
\text { logía, innovación e información. Destacan la consultoría, la } \\
\text { industria de la información, etc. (26.10\%). }\end{array}$ & $\begin{array}{l}\text { Servicios profesionales y técnicos: } \\
26.10 \%\end{array}$ \\
\hline $\begin{array}{l}\text { Quinario*: actividades de creación, organización e in- } \\
\text { terpretación de información y orientación en la toma de } \\
\text { decisiones aplicando nuevas tecnologías. Actividades sin } \\
\text { lucro para resolver necesidades normativas u obligatorias: } \\
\text { educación y salud pública, seguridad ciudadana (policía, } \\
\text { protección civil y bomberos), cultura y toda actividad regis- } \\
\text { trada por las ONG. (16.73\%). }\end{array}$ & $\begin{array}{l}\text { Educación: } 6.1 \% \text { (nivel superior } 87 \% \text { y } \\
\text { nivel medio } 13 \% \text { ) } \\
\text { Servicios de salud: } 2.8 \% \\
\text { Asistencia social:1.5\% } \\
\text { Cultural y deportivo: } 0.76 \% \\
\text { Servicio postal: } 0.25 \% \\
\text { Servicios públicos diversos: } 5.23 \%\end{array}$ \\
\hline
\end{tabular}

*Ambos son subdivisiones del sector terciario, pero con actividades muy distintas entre sí.

Fuente: elaboración propia con datos obtenidos de los documentos analizados.

\subsubsection{Medios usados por el egresado de Contaduría para conseguir empleo}

La figura 3 muestra que más de la mitad (57\%) de los contadores utilizan para la inserción laboral tres medios principales y que, tal como lo refiere la teoría del capital social, la red de contactos integrada por amigos, parientes y familiares resulta ser un componente fundamental para tener éxito al momento de buscar un empleo (41\%), situación que pone en desventaja a aquellos que 
carecen de dicho capital debido a que proceden de estratos socioeconómicos desfavorecidos (Gutiérrez y Assusa, 2019); es de interés notar que las bolsas de trabajo de las universidades escasamente contribuyen en ayudar a los egresados para colocarse en el campo laboral.

Al comparar los medios empleados que reportaron los egresados para conseguir el primer empleo y el actual, se observa una escasa evolución de los mismos, pues casi han permanecido sin cambios ya que, quienes lo han hecho, afirmaron haber utilizado el periódico y la radio (10\% contra el $11 \%$ ), bolsa de trabajo ( $7 \%$ contra $8 \%$ ), invitación de la empresa (6\% y $6 \%$ ), integración a negocio familiar ( $4 \%$ contra 3\%), recomendación de amigos ( $21 \%$ contra $14 \%)$, recomendación de familiar ( $18 \%$ contra $16 \%$ ) y relaciones laborales previas ( $2 \%$ contra $7 \%)$, evidenciándose una vez más que el capital social de los egresados tiene un papel de importancia para cambiar de empleo.

Figura 3. Medios utilizados por los contadores para conseguir empleo

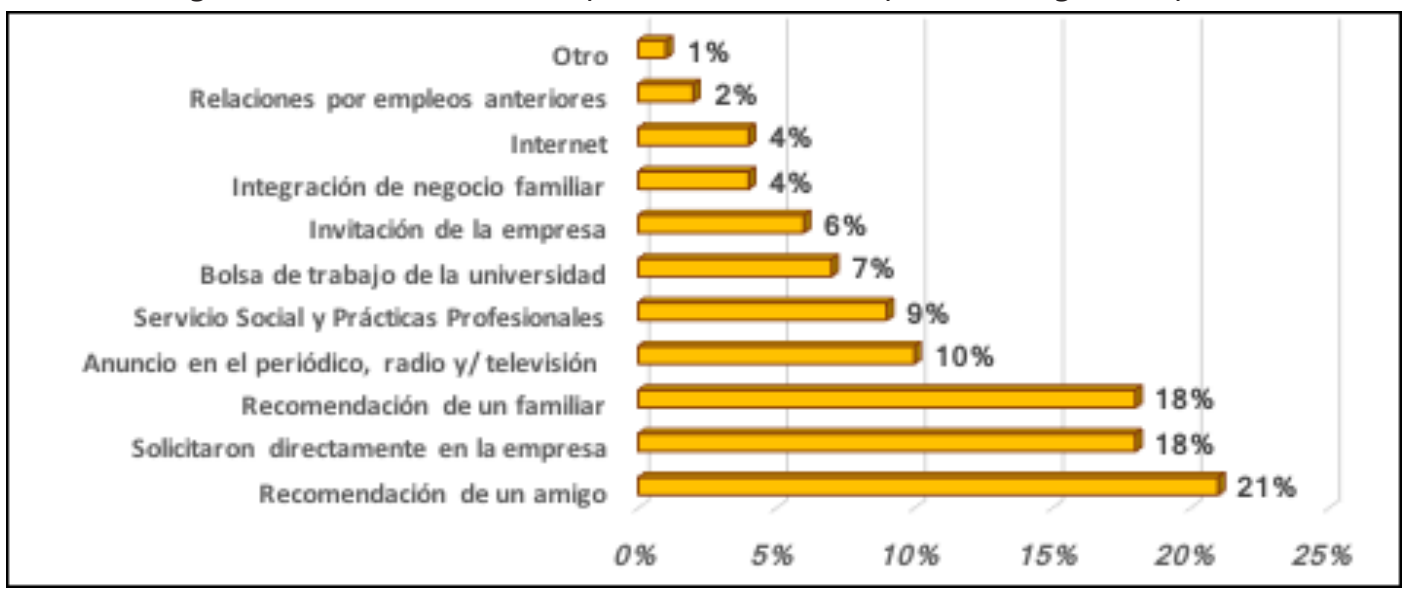

Fuente: elaboración propia con datos obtenidos de los documentos analizados.

\subsubsection{Puestos que ocupan los egresados de Contaduría y coincidencia con los estudios de licenciatura}

Las áreas en las que se desempeñan los contadores son principalmente la contable y administrativa (63\%), auditoría (20\%), fiscal (5\%) y $4 \%$ en finanzas, gerencia y nóminas, respectivamente. La tabla 8 muestra una vez más las limitadas oportunidades para que el egresado desarrolle trayectorias laborales ascendentes pues escasamente $13 \%$ se ubica en puestos directivos, mientras que casi la mitad de ellos (47.34\%) lo hacen en puestos de tipo operativo, desempeñándose como ayudantes o auxiliares contables o administrativos cuyas funciones corresponden a un egresado de bachillerato y no para uno de licenciatura.

Llama la atención que, sin importar la precariedad en el tipo de puestos que ocupan los 
egresados, estos refieren niveles altos de coincidencia entre el trabajo que desempeñan con los estudios de licenciatura pues $68 \%$ afirman que existe una total coincidencia, media en $24.43 \%$, baja en $8.69 \%$ y nula coincidencia en $10.56 \%$, proporciones que son muy similares a las asignadas a las áreas donde se desempeñan los egresados.

Tabla 8. Niveles y puestos que ocupan en las empresas los egresados de Contaduría

\begin{tabular}{|l|l|l|}
\hline \multicolumn{1}{|c|}{ Nivel directivo (13.03\%) } & \multicolumn{1}{|c|}{ Nivel medio (39.63\%) } & \multicolumn{1}{c|}{ Nivel operativo (47.34\%) } \\
\hline Coordinador General: $6.40 \%$ & Analista financiero: $9.87 \%$ & Asistente o auxiliar o ayudante: \\
Dueño o socio de empresa, des- & Jefe de oficina o área: $8.30 \%$ & $18.71 \%$ \\
pacho, entre otros: $3.32 \%$ & Subgerente o subdirector de & Actividades administrativas \\
Director General: $2.68 \%$ & área: $6.68 \%$ & generales: $18.21 \%$ \\
Director de proyectos u obras: & Jefe de departamento: $6.57 \%$ & Ventas: $4.03 \%$ \\
$0.63 \%$ & Asesor y consultor técnico: $5.35 \%$ & Otro tipo de actividad: $3.61 \%$ \\
& Docencia: $2.57 \%$ & Empleado no profesional: $1.78 \%$, \\
& & Ejecutivo de cuenta: $1.00 \%$ \\
\hline
\end{tabular}

Fuente: elaboración propia con datos obtenidos de los documentos analizados.

\subsection{Formación académica del egresado de Contaduría y su pertinencia con las exigencias del mercado laboral}

\subsubsection{Conocimientos y habilidades del egresado de Contaduría aprendidos en su formación}

Como ya se explicó anteriormente, para llevar a cabo los estudios, las IES efectuaron adaptaciones a la metodología de seguimiento de egresados de la ANUIES, por lo cual en algunos de ellos no se reportaron los conocimientos y habilidades aprendidos; sin embargo, para este apartado se procuró reunir esta información de la mayoría de los documentos a fin de tener una aproximación de la situación que reportaron los egresados; así, la tabla 9 da cuenta de altos niveles de conocimientos y habilidades que los egresados consideran haber aprendidos durante su tránsito por la universidad; sin embargo, en 11 de 24 tipos de conocimientos afirmaron estar "ni de acuerdo ni en desacuerdo" y de estos, los conocimientos sobre control interno, economía y mercadotecnia fueron los que obtuvieron un valor medio menor. Existen altos índices de acuerdo por haber aprendido y desarrollado habilidades altamente demandadas por los empleadores, tales como trabajo en equipo, comunicación efectiva, servicio al cliente, orientación a resultados, compromiso y toma de decisiones (CONOCER, 2017); no obstante, existen niveles bajos en tener una "perspectiva internacional y colaborar por personas de otras culturas". 
Tabla 9. Conocimientos y habilidades que los contadores obtuvieron durante su formación

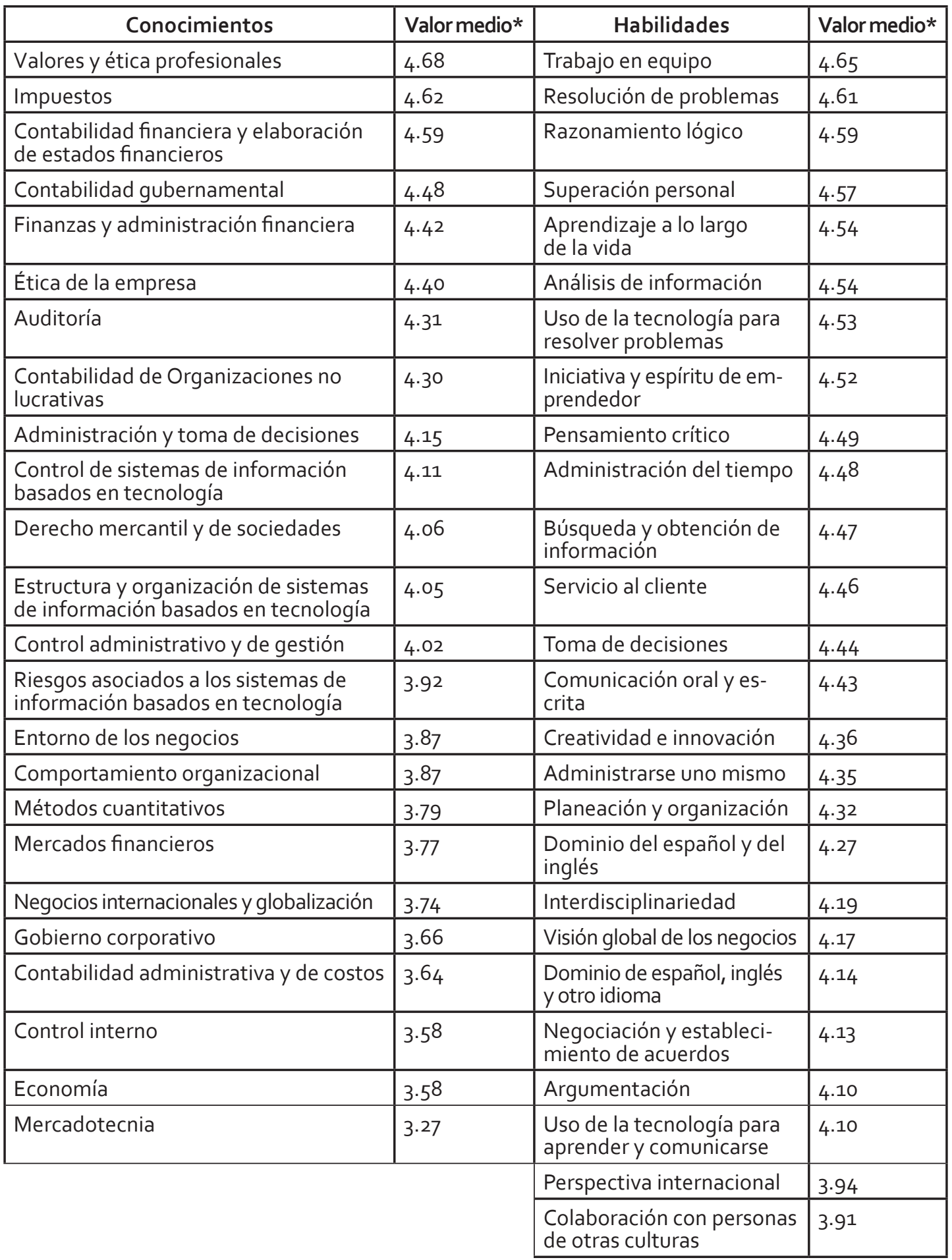

*Escala: (1:Total desacuerdo, 2: Desacuerdo), 3: Ni de acuerdo ni en desacuerdo, 4: De acuerdo, 5: Total acuerdo). Fuente: elaboración propia con datos obtenidos de los documentos analizados. 


\subsubsection{Conocimientos y habilidades que los egresados de Contaduría no adquirieron en su formación}

Los egresados mencionaron cinco importantes áreas que necesitan atenderse en la formación profesional del contador (tabla 10); por orden de importancia, destacan los conocimientos en el área de contabilidad (34.04\%), donde refieren no haber recibido suficientes conocimientos sobre sistemas y softwares contables; manejo y uso de portales de dependencias gubernamentales para el pago de impuestos, situación que corrobora $14.89 \%$ que menciona que les faltó adquirir conocimientos sobre el área de informática aplicada para la contabilidad.

Los egresados mencionan no haber recibo conocimientos para desarrollar habilidades para la comunicación (23.40\%), como hablar en público, comunicarse en forma escrita y tener dominio del idioma inglés; $y$ en cuanto a habilidades de desarrollo personal (19.14\%), mencionan que en su formación no fueron habilitados para ser creativos y usar la imaginación, tomar decisiones, trabajar bajo presión y ser autodidactas, situación que resulta grave si se toma en cuenta que estas habilidades son útiles para el fomento de la eficacia y productividad en las organizaciones (OECD, 2012).

Tabla 10. Porcentaje de egresados que no obtuvieron habilidades en su formación

\begin{tabular}{|c|c|c|}
\hline Habilidades referidas a: & Tipo y proporción & $\%$ \\
\hline $\begin{array}{c}\text { Contabilidad } \\
(34.04 \%)\end{array}$ & $\begin{array}{c}\text { Buen manejo de sistemas contables (6.0\%) } \\
\text { Manejo de páginas tributarias (4.5\%) } \\
\text { Cálculo fiscal y de impuestos (3.0\%) } \\
\text { Hacer y presentar declaraciones }(3.0 \%) \\
\text { Interpretar estados financieros }(3.0 \%) \\
\text { Contabilidad gubernamental }(1.5 \%) \\
\text { Estrategias de Impuestos }(1.5 \%) \\
\text { Fundamentar créditos fiscales (1.5\%) }\end{array}$ & $\begin{array}{l}25.00 \\
18.75 \\
12.50 \\
12.50 \\
12.50 \\
6.25 \\
6.25 \\
6.25\end{array}$ \\
\hline $\begin{array}{c}\text { Comunicación } \\
(23 \cdot 40 \%)\end{array}$ & $\begin{array}{c}\text { Comunicarse con la gente y hablar en público }(6.0 \%) \\
\text { Redacción y comunicación escrita }(4.5 \%) \\
\text { Dominio de inglés }(4.5 \%) \\
\text { Comunicación oral }(1.5 \%)\end{array}$ & $\begin{array}{l}36.36 \\
27.27 \\
27.27 \\
9.00\end{array}$ \\
\hline $\begin{array}{c}\text { Desarrollo personal } \\
(19.14 \%)\end{array}$ & $\begin{array}{c}\text { Creatividad e imaginación }(4.5 \%) \\
\text { Toma de decisiones }(1.5 \%) \\
\text { Trabajar bajo presión }(1.5 \%) \\
\text { Trato interpersonal }(1.5 \%) \\
\text { A ser autodidacta }(1.5 \%) \\
\text { Confianza }(1.5 \%) \\
\text { Dirección de equipos de trabajo }(1.5 \%)\end{array}$ & $\begin{array}{l}33.33 \\
11.11 \\
11.11 \\
11.11 \\
11.11 \\
11.11 \\
11.11\end{array}$ \\
\hline $\begin{array}{l}\text { Informática } \\
(14.89 \%)\end{array}$ & $\begin{array}{c}\text { Manejo de Software y paquetería contable (4.5\%) } \\
\text { Manejo de Excel avanzado }(3.5 \%) \\
\text { Manejo de portales de dependencias de gobierno (1.5\%) } \\
\text { Uso de herramientas de oficina }(1.5 \%)\end{array}$ & $\begin{array}{l}42.85 \\
28.57 \\
14.28 \\
14.28\end{array}$ \\
\hline $\begin{array}{l}\text { Recursos humanos } \\
(8.51 \%)\end{array}$ & $\begin{array}{l}\text { Capacitación de personal }(1.5 \%) \\
\text { Como atender a clientes }(1.5 \%) \\
\text { Manejo de personal }(1.5 \%) \\
\text { Motivación al personal }(1.5 \%)\end{array}$ & $\begin{array}{l}25.00 \\
25.00 \\
25.00 \\
25.00\end{array}$ \\
\hline
\end{tabular}

Fuente: elaboración propia con datos obtenidos de los documentos analizados. 


\subsubsection{Asignaturas no cursadas en la universidad y necesidades de capacitación} de los egresados de Contaduría

Para este apartado, una vez más se reconoce que algunos estudios no proporcionaron información al respecto; sin embargo, dada la importancia de este tema, se utilizó la que estuvo disponible en la mayoría de los documentos; así la tabla 11, en su primera columna muestra que 90.53\% de los egresados refieren no haber cursado asignaturas especializadas del área de contribuciones (cálculo y pago de impuestos de personas físicas y morales, e impuestos estatales), informática (software contable y TIC aplicadas a contabilidad) y de contabilidades especiales (gubernamental, hotelera, entre otros), cuyos contenidos son exigidos para el desarrollo de su trabajo, tal como lo muestra la columna central de la tabla, y que al no habérseles otorgado en las aulas tuvieron la necesidad de capacitarse una vez que egresaron y estaban laborando.

Esta información es importante para que las IES establezcan estrategias desde los departamentos de educación continua o bien desde el diseño curricular de sus planes de estudio y atiendan estos vacíos de conocimiento que reportan los egresados a fin de ofrecer la carrera con un alto grado de coincidencia con las necesidades del sector de empleadores y responder a los diversos campos de acción de este tipo de profesionales (IMCP, 2017). 
Tabla 11. Asignaturas no cursadas, asignaturas más utilizadas y áreas que exigen capacitación

\begin{tabular}{|c|c|c|}
\hline $\begin{array}{c}\text { Materias no vistas en la carrera y } \\
\text { necesarias en el trabajo }\end{array}$ & $\begin{array}{l}\text { Materias de mayor peso } \\
\text { en el trabajo }\end{array}$ & $\begin{array}{c}\text { Areas donde se } \\
\text { capacitan } \\
\text { constantemente }{ }^{\star}\end{array}$ \\
\hline Área contribuciones (34.75\%): & \multirow{31}{*}{ 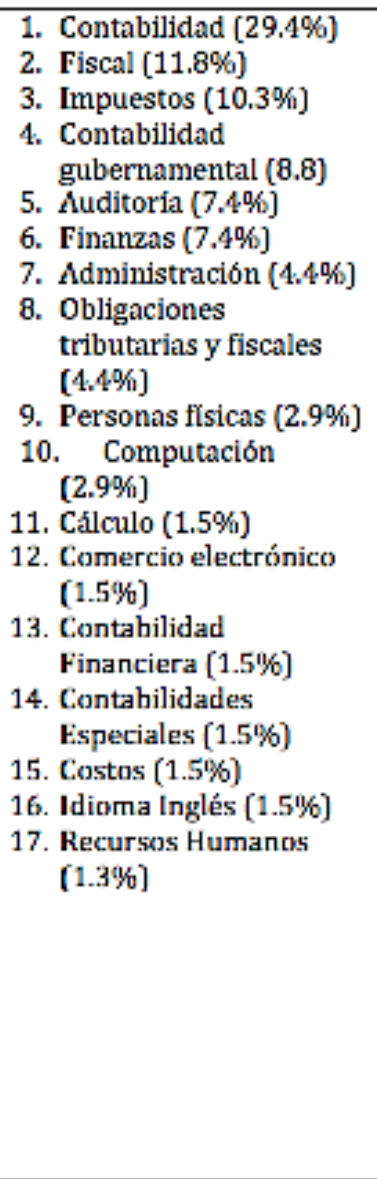 } & \multirow{31}{*}{$\begin{array}{l}\text { 1. Temas fiscales } \\
\text { 2. Paquetes o } \\
\text { software contables } \\
\text { 3. Auditoria } \\
\text { 4. Costos } \\
\text { 5. Finanzas } \\
\text { 6. Derecho } \\
\text { 7. Proceso } \\
\text { administrativo } \\
\text { 8. Proyectos de } \\
\text { inversion } \\
\text { 9. Paquetes } \\
\text { administrativos } \\
\text { 10. Mercadotecnia } \\
\text { 11. Recursos Humanos } \\
\text { 12. Comercio } \\
\text { electrónico } \\
\text { 13. Comercio } \\
\text { Internacional }\end{array}$} \\
\hline 1. Personas fisicas y morales $[9.16 \%]$ & & \\
\hline 2. Impuestos $(4.57 \%)$ & & \\
\hline 3. Actualización fiscal [4.57\%] & & \\
\hline 4. Contabilidad fiscal $(4.57)$ & & \\
\hline 5. Impuestos estatales [ $4.57 \%]$ & & \\
\hline 6. Ley del Impuesto Sobre la Renta & & \\
\hline$(4.57 \%)$ & & \\
\hline 7. Fiscal $(2.74 \%)$ & & \\
\hline $\begin{array}{l}\text { Área informática }(\mathbf{3 0 . 1 8} \%) \text { : } \\
\text { 1. Paquetes o software contable }\end{array}$ & & \\
\hline$(10.67 \%)$ & & \\
\hline 2. Informatica general ( $8.84 \%)$ & & \\
\hline 3. TIC para la contabilidad $[6.10 \%]$ & & \\
\hline 4. Excel $(4.57 \%)$ & & \\
\hline $\begin{array}{l}\text { Área contabilidad (25.60\%): } \\
\text { 1. Contabilidad gubernamental }[8.53 \%)\end{array}$ & & \\
\hline 2. Contabilidad hotelera $(4.57 \%)$ & & \\
\hline 3. Sistemas de información contable & & \\
\hline$(4.57 \%)$ & & \\
\hline 4. Contabilidad de costos $[4.57 \%$ ] & & \\
\hline 5. Auditoría (3.00\%) & & \\
\hline Área finanzas (2.25\%): & & \\
\hline 1. Finanzas (1.80\%) & & \\
\hline 2. Presupuestos $(0.45 \%)$ & & \\
\hline \multirow{4}{*}{$\begin{array}{l}\text { Área recursos humanos }(2.22 \%) \text { : } \\
\text { 1. Leyes laborales }(0.88 \%) \\
\text { 2. Nóminas (0.89\%) } \\
\text { 3. Seguridad social }(0.45 \%)\end{array}$} & & \\
\hline & & \\
\hline & & \\
\hline & & \\
\hline Otras (5.00\%): & & \\
\hline 1. Inglés $(3.59 \%)$ & & \\
\hline 2. Álgebra y estadística $[0.91 \%)$ & & \\
\hline 3. Calidad $(0.50 \%)$ & & \\
\hline
\end{tabular}

*Se presentan por jerarquía en forma descendente.

Fuente: elaboración propia con datos obtenidos de los documentos analizados.

\subsubsection{Grado de exigencia en conocimientos y habilidades en el desempeño profesional del egresado de Contaduría}

Con el fin de corroborar lo antes descrito, se indagó sobre el nivel de exigencias en cuanto a conocimientos y habilidades. La tabla 12 muestra que $92 \%$ de los contadores afirman tener exigencias entre media y alta en la habilidad para aplicar conocimientos y tomar decisiones, para identificar y solucionar problemas (90\%), razonamiento lógico y analítico $(86.80 \%)$ y habilidades de naturaleza administrativa (86.55\%). Llama la atención que $62.40 \%$ refieren de ninguna a baja exigencia en mostrar creatividad, asumir responsabilidades (52.95\%), trabajar en equipo (51.20\%), disposición para manejar riesgos (50.40\%) y habilidades para comunicarse de manera 
oral, escrita y gráfica (49.65\%); lo anterior es explicable pues este tipo de habilidades son poco requeridas, según el tamaño de la empresa, tipo de actividades y el nivel operativo donde laboran la mayoría de los egresados.

Tabla 12. Conocimientos y habilidades exigidos en el trabajo para los contadores

\begin{tabular}{|l|l|l|l|l|}
\hline \multicolumn{1}{|c|}{ Conocimientos } & \multicolumn{1}{c|}{$\mathbf{1}$} & \multicolumn{1}{c|}{$\mathbf{2}$} & \multicolumn{1}{c|}{$\mathbf{3}$} & \multicolumn{1}{|c|}{} \\
\hline Conocimientos generales de la disciplina & $5.75 \%$ & $9.20 \%$ & $44.60 \%$ & $40.45 \%$ \\
\hline Conocimientos especializados & $7.50 \%$ & $11.95 \%$ & $44.85 \%$ & $35.70 \%$ \\
\hline Conocimientos de lenguas extranjeras & $1.50 \%$ & $19.40 \%$ & $49.30 \%$ & $29.90 \%$ \\
\hline Habilidades para el manejo de paquetes computacionales & $4.50 \%$ & $9.70 \%$ & $39.85 \%$ & $45.95 \%$ \\
\hline Razonamiento lógico y analítico & $4.75 \%$ & $8.45 \%$ & $40.60 \%$ & $46.20 \%$ \\
\hline Habilidad para aplicar conocimientos & $3.50 \%$ & $4.50 \%$ & $33.90 \%$ & $58.10 \%$ \\
\hline Habilidad para tomar decisiones & $3.50 \%$ & $4.50 \%$ & $40.85 \%$ & $51.15 \%$ \\
\hline Habilidad para identificar y solucionar problemas & $3.00 \%$ & $6.95 \%$ & $33.90 \%$ & $56.15 \%$ \\
\hline Habilidad para buscar información pertinente y actualizada & $8.00 \%$ & $19.40 \%$ & $35.90 \%$ & $36.70 \%$ \\
\hline Habilidad para procesar y utilizar información & $5.50 \%$ & $17.15 \%$ & $38.35 \%$ & $39.00 \%$ \\
\hline Habilidad para trabajar en equipo & $11.25 \%$ & $39.95 \%$ & $36.60 \%$ & $12.20 \%$ \\
\hline Habilidad para planear, organizar y dirigir el trabajo & $5.75 \%$ & $11.95 \%$ & $37.60 \%$ & $44.20 \%$ \\
\hline Habilidad administrativa & $4.75 \%$ & $8.70 \%$ & $41.10 \%$ & $45.45 \%$ \\
\hline Disposición de aprender constantemente & $4.50 \%$ & $9.45 \%$ & $39.85 \%$ & $46.20 \%$ \\
\hline Disposición para el manejo de riesgos & $12.70 \%$ & $37.70 \%$ & $30.15 \%$ & $19.45 \%$ \\
\hline Habilidades para las relaciones públicas & $5.00 \%$ & $11.20 \%$ & $39.85 \%$ & $43.95 \%$ \\
\hline Habilidades para la comunicación oral, escrita y/o gráfica & $11.20 \%$ & $38.45 \%$ & $33.60 \%$ & $17.20 \%$ \\
\hline Puntualidad y formalidad & $7.00 \%$ & $41.5 \%$ & $27.40 \%$ & $24.10 \%$ \\
\hline Buena presentación & $9.00 \%$ & $39.00 \%$ & $35.35 \%$ & $17.10 \%$ \\
\hline Asumir responsabilidades & $6.00 \%$ & $46.95 \%$ & $27.85 \%$ & $19.20 \%$ \\
\hline Creatividad & $13.75 \%$ & $48.65 \%$ & $28.90 \%$ & $8.70 \%$ \\
\hline Identificación con la empresa & $3.0 \%$ & $31.3 \%$ & $53.7 \%$ & $11.9 \%$ \\
\hline
\end{tabular}

Escala: 1(Nulo), 2 (Bajo), 3 (Medio), 4 (alto) y, expresadas en porcentajes.

Fuente: elaboración propia con datos obtenidos de los documentos analizados.

\subsubsection{Opinión del egresado de Contaduría sobre su carrera universitaria}

Sin considerar las escasas oportunidades que ofrece el mercado de trabajo para el desarrollo profesional y laboral del egresado de contaduría, las dos terceras partes (66.26\%) afirman que sí volverían a estudiar la carrera, en tanto 33.74\% no lo haría. Los niveles de satisfacción son 
diversos, tal como se muestra en la tabla 13; dentro de la escala satisfecho a muy satisfecho destacan el responder a problemas del trabajo y su naturaleza o contenido ( $94 \%$ respectivamente), el ambiente de trabajo (88\%), el coordinar un equipo de trabajo (86.6\%) y poner en práctica los conocimientos adquiridos en la universidad, así como la posibilidad de realizar ideas propias (85\% respectivamente).

Estos niveles altos de satisfacción deberían evaluarse utilizando algunas variables moderadoras como el estrato social y los antecedentes académicos de los padres, pues la percepción es distinta cuando se trata de egresados "herederos" en contraste con los "pioneros", es decir, aquellos que por primera vez en su familia tienen acceso a la educación superior y cuyas expectativas salariales y laborales no son tan exigentes (De Garay, 2002). Sin embargo, se encontró que $34.3 \%$ afirman estar de "nada a poco satisfechos" por la posición jerárquica, reconocimiento profesional (20.9\%), hacer algo de provecho para la sociedad (19.4) y responder a problemas de relevancia social (16.4\%).

Tabla 13. Aspectos para el nivel de satisfacción por cursar la Licenciatura en Contaduría

\begin{tabular}{|l|l|l|l|c|}
\hline \multicolumn{1}{|c|}{ Aspectos } & \multicolumn{1}{c|}{$\mathbf{1}$} & \multicolumn{1}{c|}{$\mathbf{2}$} & $\mathbf{3}$ & $\mathbf{4}$ \\
\hline La puesta en práctica de los conocimientos adquiridos en la licenciatura & 1.5 & 13.4 & 61.2 & 23.9 \\
\hline La posibilidad de realizar ideas propias & -- & 14.9 & 59.7 & 25.4 \\
\hline El reconocimiento profesional alcanzado & 1.5 & 19.4 & 49.3 & 29.9 \\
\hline El trabajo en equipo & -- & 16.4 & 56.7 & 26.9 \\
\hline La posibilidad de coordinar un equipo de trabajo & 1.5 & 11.9 & 58.2 & 28.4 \\
\hline La posibilidad de responder a problemas del trabajo & -- & 6.0 & 47.8 & 46.3 \\
\hline El contenido del trabajo & -- & 6.0 & 62.7 & 31.3 \\
\hline El ambiente de trabajo & -- & 11.9 & 50.7 & 37.3 \\
\hline La posición jerárquica alcanzada & 3.0 & 31.3 & 53.7 & 11.9 \\
\hline La posibilidad de responder a problemas de relevancia social & 1.5 & 14.9 & 64.2 & 19.4 \\
\hline La posibilidad de hacer algo de provecho para la sociedad & 1.5 & 17.9 & 52.2 & 28.4 \\
\hline
\end{tabular}

Escala: 1(Nada satisfecho), 2 (Poco satisfecho), 3 (Satisfecho), 4 (Muy satisfecho) y, expresadas en porcentajes. Fuente: elaboración propia con datos obtenidos de los documentos analizados.

\section{Conclusiones}

De acuerdo con los resultados obtenidos, se concluye que en el caso concreto que se investigó, una alta proporción de egresados de contaduría se inserta prontamente en el mercado de trabajo en el lapso de un año después de concluir los estudios universitarios; no obstante, llama la atención que dicha proporción sea inferior a la reportada en las estadísticas oficiales, quizá debido a las limitantes metodológicas que pudieron presentar los diversos estudios recuperados 
y analizados para este trabajo. La mayoría labora en empresas privadas y escasamente generan fuentes de empleo mediante la creación de empresas o negocios propios. Para la inserción laboral por primera vez, así como para cambios de empleo posteriores, juega un papel importante la teoría del capital social expresado mediante la red de relaciones o contactos que tiene el egresado, situación que coloca en desventaja a aquellos que carecen de estas, sobre todo a los que proceden de estratos socioeconómicos bajos y son pioneros en acceder a la formación universitaria. Para la inserción laboral tienen que cumplir tres requisitos: pasar una entrevista formal, tener experiencia laboral y estar titulados, mismos que de no cumplirlos se convierten en serias limitantes para encontrar empleo.

El mercado de trabajo para el contador está integrado en su mayoría por micro y pequeñas empresas (Mypes) y en menor medida por medianas y grandes empresas, siendo en el sector terciario (comercio y servicios) y sus subdivisiones donde laboran la mayoría, escasamente en el secundario y casi nulo en el primario. Existe una limitada capacidad del mercado laboral para el desarrollo laboral y profesional de los contadores, pues les ofrece condiciones laborales precarias, como el sueldo que en promedio es menor a $\$ 10,000.00$ mensuales, jornadas de trabajo que en algunos casos superan las 40 horas semanales, tal como lo estipulan las leyes laborales, sin garantía de seguridad ni estabilidad laboral, otorgándoles a casi la mitad de ellos contratos principalmente por tiempo u obra determinada. El mercado de trabajo presenta limitadas oportunidades para que los contadores desarrollen trayectorias laborales ascendentes pues, a casi cinco años de su inserción, una minoría ocupa puestos directivos, en tanto la mitad de ellos se ubica en áreas operativas como auxiliares contables o administrativos, que no corresponden a un egresado de licenciatura; no obstante, sin importar la precariedad laboral, refieren niveles altos de coincidencia entre el trabajo con los estudios de licenciatura pues, en orden de importancia, se desempeñan en las áreas contable y administrativa, auditoría, fiscal y finanzas.

Los egresados, durante su tránsito por la universidad desarrollaron habilidades altamente demandadas en el mercado de trabajo, tales como trabajo en equipo, comunicación efectiva, servicio al cliente, orientación a resultados, compromiso y toma de decisiones; sin embargo, un poco más de la tercera parte mencionaron que no les ofreció asignaturas especializadas del área de contribuciones, uso de paquetería contable y contabilidades especiales, sobre todo de tipo gubernamental y de hotelería, por lo cual tuvieron la necesidad de capacitarse. Enfrentan exigencias en aplicar conocimientos y tomar decisiones, identificar y solucionar problema, razonamiento lógico y analítico, y habilidades de naturaleza administrativa. Debido a las demandas del sector de empleadores para incrementar la productividad de las organizaciones, las áreas donde más necesitan capacitarse, en orden de importancia, son: sistemas y softwares contables, manejo y uso de portales de dependencias gubernamentales, habilidades para comunicarse en forma oral y escrita, dominio del idioma inglés, tomar decisiones, trabajar bajo presión y ser autodidactas.

Diólo@os 
Se observa que la dinámica entre los procesos educativos para la formación del contador y las condiciones del mercado de trabajo son cambiantes y en ocasiones divergentes; por un lado, las universidades preparan a los egresados con conocimientos y habilidades para desempeñarse en niveles directivos o jerárquicos altos en cualquier tipo de empresas, mientras que el mercado de trabajo les brinda escasas posibilidades para desarrollar trayectorias profesionales y laborales ascendentes y positivas que se evidencian en la devaluación de la formación universitaria al ofrecer en su mayoría puestos de trabajo en Mipymes, en niveles operativos que distan del perfil de egreso del contador. Las limitantes del mercado de trabajo en aspectos como el tamaño y sector económico de las empresas, tipo de actividades y el nivel operativo donde se ubican los egresados, bien pueden explicar los bajos salarios y las largas jornadas de trabajo, así como los niveles bajos de exigencia para asumir responsabilidades, trabajar en equipo, disposición para manejar riesgos y habilidades para comunicarse de manera oral, escrita y gráfica.

A pesar de las limitadas oportunidades que les ofrece el mercado de trabajo, dos terceras partes de los egresados volverían a estudiar la carrera, situación que merece ser investigada de manera más detallada a fin de identificar si el estrato social de procedencia y los antecedentes académicos de los padres se constituyen en variables moderadoras pues, de acuerdo con algunos teóricos, los niveles de satisfacción profesional y laboral difieren entre individuos que pertenecen a determinada clase social que tiene un capital social, educativo y cultural que heredan de los padres, en relación con aquellos de estratos socioeconómicos bajos que por primera vez en su familia han tenido la oportunidad de cursar estudios universitarios, cifrando en estos sus expectativas para su movilidad social.

\section{Referencias bibliográficas}

Aguirre, R.; M. Chávez (2010). El contador público y el trabajo profesional como auditor. México: ITSON.

ANUIES (2003). Mercado laboral de profesionistas en México. Asociación Nacional de Universidades e Instituciones de Educación Superior.

Armendáriz, J.; J. Vázquez; S. De la Garza; A. Lara (2016). Perspectiva laboral de los futuros egresados de las licenciaturas de la Facultad de Contaduría y Administración de Monclova, Coahuila. Revista Administración y Finanzas, 3(8), 52-65.

Barragán, N. (2004). Seguimiento a egresados de Contaduría y Administración: instrumento estratégico de la educación superior. Innovaciones de Negocios, 1(2), 301-319.

Bezies, P.; J. Pérez; N. González, L. Elizalde, B. Olvera, M. López, A. Ordaz, I. Gayosso, A. Ángeles, A. Godínez, A. Acaxtenco, D. González y J. Ortiz (2017). Resultados del Estudio de Egresados de la Licenciatura en Contaduría. México: Universidad Autónoma del Estado de Hidalgo. 
BID (2003). Se buscan buenos empleos. Los mercados laborales en América Latina. Washington: Banco Interamericano de Desarrollo.

Brito, J.; V. Ferreiro; A. Garambullo (2017). Evaluación de la pertinencia y calidad del programa educativo de licenciatura en contaduría: Estudio de empleadores y egresados. Revista lberoamericana para la Investigación y el Desarrollo Educativo, 8(15), 01-27.

Burgos, B.; K. López (2010). La situación del mercado laboral de profesionistas. Revista de la Educación Superior, 39(4), 19-33.

Cardona, M.; I. Montes; J. Vásquez; M. Villegas; T. Brito (2007). Capital Humano: Una mirada desde la educación y la experiencia laboral. Cuaderno de Investigación, 6, 01-36.

Carrera, M.; M. Gómez; A. Pérez (2012). Análisis de satisfacción con la carrera: Contador Público. Generaciones 1996-2008. México: Universidad Juárez del Estado de Durango.

CONOCER (2017). Encuesta Anual sobre Competencias en México. Informe de resultados 2017. México: Consejo Nacional de Normalización y Certificación de Competencias Laborales.

Damián, J. (2018). El mercado de trabajo del Licenciado en Administración en México: Aproximación al estudio de sus características. Revista Venezolana de Gerencia, 23(84), 848-871.

Damián, J.; E. Montes; LI. Arellano (2010). Los estudios de opinión de empleadores. Estrategia para elevar la calidad de la educación superior no universitaria. Revista Iberoamericana sobre Calidad, Eficacia y Cambio en Educación, 8(3), 179-203.

De Agüero, M. (1999). Un punto de vista sobre los conocimientos del contador público. Revista Contaduría y Administración, 195, 81-87.

De Agüero, M.; J. Torres (2014). Panorama de la educación superior en México. En Torres, J. (coord.). El futuro de nuestras carreras: Contaduría, Administración, Informática en la sociedad mexicana del siglo XXI. México: UNAM, 13-18.

De Garay, A. (2002). Un sistema de educación superior, dos realidades distintas: La universidad pública y la universidad privada. Revista de la Educación Superior, 122, 69-77.

Durán, M.; M. Mejía; A. Arturo (2012). Competencias genéricas y profesionales: Un enfoque analítico de la licenciatura en contaduría. XVII Congreso Internacional de Contaduría, Administración e Informática. México: UNAM.

Echavarría, A. (2013). Mercado de trabajo para los profesionistas de la Contaduría y la Administración: Una visión global y el caso de Cd. Victoria. México: Universidad Autónoma de Tamaulipas.

ENOE (2010). Encuesta Nacional de Ocupación y Empleo: ENOE 2010. México: Instituto Nacional de Estadística y Geografía/Secretaría del Trabajo y Previsión Social.

Espino, J. (2017). Formación de profesionistas y ciudadanos. El contador público como promotor académico. Revista Contaduría Pública, 50-54.

Galván, J.; A. Muñoz; Ll. Díaz (2013). El programa de seguimiento a egresados como medio para aportar elementos de mejora a la formación profesional. En López, M.; I. Espitia; P. Chávez; 
G. Gutiérrez (comps.). Gestión e Innovación en las Ciencias Administrativas y Contables. México: Universidad Michoacana de San Nicolás de Hidalgo, 589-600.

Gamboa, S.; A. Vázquez; M. Hernández (2011). Diagnóstico del entorno laboral en San Luis Potosí del contador público egresado de la UASLP. XV Congreso Internacional de Investigación en Ciencias Administrativas. México: UASLP.

García, M.; G. Valenzuela (2007). El perfil de egreso del contador público en la ciudad de Puebla. http://www.comie.org.mx/congreso/memoriaelectronica/v09/.../at02/PRE1178921532. pdf

González, C.; G. Ortega (2015). Empleabilidad de los egresados de la Carrera de Contaduría Pública. Revista Iberoamericana para la Investigación y el Desarrollo Educativo, 6(11), 01-21.

González, C. (2015). Empleabilidad de los egresados de la Carrera de Contaduría Pública del Centro Universitario de los Altos. XX Congreso Internacional de Contaduría, Administración e Informática. México: UNAM.

Grande, B. (2007). El perfil profesional del Contador Público en el Instituto Politécnico Nacional ante las nuevas tendencias laborales. Tesis inédita de maestría en ciencias con especialidad en Administración y Desarrollo de la Educación. México: IPN.

Gutierrez, A.; G. Assusa (2019). Estrategias de inserción laboral y capital social. Un estudio sobre jóvenes de clases populares en Córdoba, Argentina. Última Década, 27(51), 160-191.

Gutiérrez, H.; B. Morales (2014). Perspectiva y futuro de la contaduría pública. Un análisis crítico-reflexivo. Caso de estudio de la Universidad de Guanajuato. Innovaciones de Negocios, $11(22), 313-327$.

Gutiérrez, L.; J. Zúñiga; J. González (2012). Percepción del sector empresarial sobre el desempeño laboral del contador público egresado de la FCA de la UA de C. XV Congreso Internacional sobre Innovaciones en Docencia e Investigación en Ciencias Económico Administrativas. México: Universidad Autónoma de Chihuahua.

Guzmán, S.; M. Febles.; A. Corredera (2007). Factores que facilitan la inserción en el mercado laboral. http://www.comie.org.mx/congreso/memoriaelectronica/v09/ponencias/at02/ PRE1178553220.pdf

Hall, R.; M. Lieberman (2005). Microeconomía: Principios y aplicaciones. México: Thomson Editores.

Hernández, M. (2009). Análisis estadístico de las bases de datos de egresados 2004-2009. México: BUAP.

IMCO (2017). Compara carreras. http://www/imco.org.mx/comparacarreras

IMCP (2017). El contador público: La mejor elección para una visión global de la empresa. $9^{\circ}$ Concurso de Ensayo Universitario Carlos Pérez del Toro. https://www.ccpm.org.mx/espaciouniversitario/trabajos ganadores/trabajos noveno/4o lugar.pdf 
Javier, M.; L. Arguelles; A. Aké (2011). El contador público y la administración de las Pymes del sector turístico en San Francisco de Campeche, Campeche. XVI Congreso Internacional de Contaduría, Administración e Informática. México: UNAM.

Leopoldo, J.; F. Ramírez; S. Cuarenta; M. José (2016). Análisis comparativo entre el perfil de egreso del contador público y las exigencias del mercado laboral. Revista lberoamericana de Ciencias, 3(7), 168-177.

López, C.; R. González; L. Rodríguez (2013). Resultado del programa de seguimiento de egresados de las licenciaturas en Contaduría y Administración de Empresas de la Universidad Autónoma del Carmen. En López, M.; I. Espitia; P. Chávez; G. Gutiérrez (comps.). Gestión e Innovación en las Ciencias Administrativas y Contables. México: Universidad Michoacana de San Nicolás de Hidalgo, 517-534.

Martínez, U.; M. Flores; J. Flores (2015). Estudios sobre la ocupación laboral de los egresados de la Licenciatura en Contaduría. XX Congreso Internacional de Contaduría, Administración e Informática. México: UNAM.

Montoya, J.; G. Farías (2013). Diferencias entre la formación en contaduría recibida en la universidad y las demandas del mercado laboral en México: Un estudio descriptivo. XVIII Congreso Internacional de Contaduría, Administración e Informática. México: UNAM.

Montoya, J.; G. Farías (2014). Habilidades profesionales importantes para el desempeño de la contaduría pública en México. XIX Congreso Internacional de Contaduría, Administración e Informática. México: UNAM.

Morales, M. (2016). Estudio descriptivo de la calidad de vida laboral en profesionales de la contaduría en la ciudad de Toluca en 2015. Tesis inédita de Maestría en Administración de Recursos Humanos. México: Universidad Autónoma del Estado de México.

Munguía, H.; M. Quintal (2012). Estudio de egresados de la Universidad Estatal de Sonora. México: UES.

OECD (2012). Looking to 2060: Long-term Global Growth Prospects. https://www.oecd.org/eco/ outlook/2060 policy paper FINAL.pdf

Padilla, J. (2017). La inserción al mercado laboral de los egresados de los programas de licenciaturas administrativas de Centro Universitario de Los Altos. Tesis inédita de Maestría en Administración de Negocios. México: Universidad de Guadalajara.

Palma, R., S. Pérez y S. Vilchis (2013). La certificación de las competencias en las TIC como factor de desempeño en los egresados universitarios de la Facultad de Contaduría y Administración de la Universidad Autónoma del Estado de México. En M. López, I. Espitia, P. Chávez y G. Gutiérrez (comps.). Análisis organizacional, política científica y desarrollo tecnológico. México: Universidad Michoacana de San Nicolás de Hidalgo, 422-437.

Pedraza, J. (2016). Condiciones generadoras de malestar laboral: el caso de los contadores públicos en las empresas del sector farmacéutico en Bogotá. Tesis de maestría. Bogotá. Universidad Nacional de Colombia. 
Planas, J. (2014), Adecuar la oferta de educación a la demanda de trabajo. ¿Es posible? Una crítica a los análisis "adecuacionistas" de relación entre formación y empleo. México: ANUIES.

Quintana, M.; S. Mitre; J. Sánchez (2013). La profesión de contaduría pública: Nuevos retos de los egresados de la Facultad Autónoma de Tlaxcala. En López, M.; I. Espitia; P. Chávez; G. Gutiérrez (comps.). Análisis organizacional, política científica y desarrollo tecnológico. México: Universidad Michoacana de San Nicolás de Hidalgo, 889-898.

Ramos, J. (2016). El contador público en la actualidad. http://www.itson.mx/publicaciones/pacioli/Documents/no67/

Rodales, M.; M. Chávez (2018). Estudio a empleadores de egresados de la licenciatura en Contaduría de la Universidad Michoacana de San Nicolás de Hidalgo. En Hernández, V.; E. Galeana; M. Valenzo; P. Chávez (comps.). Emprendimiento, negocios y la responsabilidad social en las organizaciones. México: Universidad Michoacana de San Nicolás de Hidalgo, 609-624.

Rodríguez, M.; E. Cotera; A. Soberanes (2012). Seguimiento de egresados de la Licenciatura en Contaduría del Centro Universitario UAEM Amecameca. En López, M.; I. Espitia; J. Martínez; M. Valenzo (comps.). Competitividad y sustentabilidad empresarial (pp. 188-196). México: Universidad Michoacana de San Nicolás de Hidalgo.

Román, J. (2014). Mercado laboral para administradores y contadores: retos y oportunidades desde la visión empresarial. Revista Internacional de Administración y Finanzas, 7(5), 91-101.

Román, J. (2014). Opinión de empleadores respecto a los egresados de Administración y Contaduría. Retos y oportunidades. https://www.azc.uam.mx/sieee/cuartoseminario/ponencias/ ponencia25.pdf

Román, J.; A. Gordillo (2013). Demandas formativas y mercado laboral de contadores y administradores, desde la óptica empresarial. En López, M.; I. Espitia; P. Chávez; G. Gutiérrez (comps.). Gestión e Innovación en las Ciencias Administrativas y Contables (pp. 496-516). México: Universidad Michoacana de San Nicolás de Hidalgo.

Román, J.; R. Franco (2013). Mercado laboral de egresados, desde la visión de empleadores. Ponencia presentada en el XVIII Congreso Internacional de Contaduría, Administración e Informática. México: UNAM.

Román, J.; A. Gordillo (2013). Áreas de oportunidad para administradores y contadores desde la perspectiva de empleadores. En López, M.; I. Espitia; P. Chávez; G. Gutiérrez (comps.). Análisis organizacional, política científica y desarrollo tecnológico. México: Universidad Michoacana de San Nicolás de Hidalgo, 193-207.

Román, J.; M. Enciso (2012). Mercado laboral de administradores y contadores en Chiapas desde la visión empresarial. En Administración para el Desarrollo, 3, 19-46.

Ruiz, F.; J. Zúñiga; J. González (2005). Pertinencia de las carreras que ofrece la Facultad de Contaduría y Administración-Unidad Norte de la Universidad Autónoma de Coahuila. Ponencia presentada en el IX Congreso Internacional de Investigación en Ciencias Administrativas. México: UADY. 
Sarur, M.; J. Romero (2016). La ética del contador independiente. UNIVERSITA CIENCIA, 4(14), 79-93. Talavera, R.; M. Plazola; M. Berrelleza (2013). Inserción laboral de los potenciales a egresar en la Licenciatura en Contaduría. En López, M.; I. Espitia; P. Chávez; G. Gutiérrez (comps.). Análisis organizacional, política científica y desarrollo tecnológico (pp. 695-707). México: Universidad Michoacana de San Nicolás de Hidalgo.

Treviño, Y.; E. Anchondo; I. Polanco (2011). Inserción laboral de los egresados de la carrera de Contador Público. Generación diciembre 2010 de la Facultad de Contaduría y Administración de la Universidad Autónoma de Chihuahua.http://www.fca.uach.mx/apcam/2014/04/08/ Ponencia 142-UACH.pdf

Treviño, Y.; I. Polanco; F. Porras (2012). Inserción laboral de los egresados de la carrera de Contador Público. Generaciones 2010 y 2011 de la Facultad de Contaduría y Administración de la Universidad Autónoma de Chihuahua. http://www.fca.uach.mx/apcam/2014/04/05/ Ponencia 99-UACH.pdf

Torres, J. (2014). El futuro de nuestras carreras: Contaduría, Administración, Informática en la sociedad mexicana del siglo XXI. México: UNAM.

Toscano, J.; T. Salgado (2018). El egresado de la FCCA en el mercado laboral. En Hernández, V.; E. Galeana; M. Valenzo; P. Chávez (comps.). Emprendimiento, negocios y la responsabilidad social en las organizaciones. México: Universidad Michoacana de San Nicolás de Hidalgo, 764-778.

Toscano, J.; R. Toscano; C. Toscano (2011). Proyecto de egresados de la Carrera de Licenciado en Contaduría. En Figueroa, E.; M. López (comps.). Competitividad organizacional. Solución a los problemas actuales (pp. 787-798). México: Universidad Michoacana de San Nicolás de Hidalgo.

Vera, M.; J. Soriano; L. Linares (2017). Competencias exigidas a los egresados de la licenciatura en contaduría pública, para insertarse al mercado laboral que ofertan las empresas. Caso de estudio. Horizontes de la Contaduría en las Ciencias Sociales, 4(7), 104-117. 